Originally published as:

Lithium isotopic fractionation during weathering and erosion of shale

Grit Steinhoefel, G., Brantley, S. L., Fantle M. S. (2021): Lithium isotopic fractionation during weathering and erosion of shale. Geochimica et Cosmochimica et Acta 295, 155-177. doi: 10.1016/j.gca.2020.12.006 


\title{
Lithium isotopic fractionation during weathering and erosion of shale
}

Geochimica et Cosmochimica et Acta (2021), doi: 10.1016/j.gca.2020.12.006

Grit Steinhoefel ${ }^{1 *}$, Susan L. Brantley ${ }^{1,2}$, Matthew S. Fantle ${ }^{1}$

${ }^{1}$ Department of Geosciences, Pennsylvania State University, University Park PA 16802 (USA)

${ }^{2}$ Earth and Environmental Systems Institute, Pennsylvania State University, University Park PA 16802 (USA)

Corresponding author*: Grit Steinhoefel, grit.steinhoefel@awi.de, phone: +49+49(471)48312093, present address: Alfred Wegener Institute, Helmholtz Centre for Polar and Marine Research, D-27570 Bremerhaven (Germany).

Highlights:

- We investigate Li isotopes and concentration in a shale catchment

- The relative rates of Li incorporation into secondary minerals control $\delta^{7} \mathrm{Li}$ of water

- Subsurface erosion of clay particles controlls $\delta^{7} \mathrm{Li}$ and Li depletion in soils

- Subsurface erosion in shale is likely a prominent component of global weathering

\begin{abstract}
Clay weathering in shales is an important component of the global Li budget because $\mathrm{Li}$ is mobilized from Li-rich clay minerals and shale represents about one quarter of the exposed rocks on Earth. We investigate $\mathrm{Li}$ isotopes and concentrations to explore implications and mechanisms of Li isotopic fractionation in Shale Hills, a first-order catchment developed entirely on shale in a temperate climate in the Appalachian Mountains, northeastern USA. The $\mathrm{Li}$ isotopic compositions ( $\delta^{7} \mathrm{Li}$ ) of aqueous $\mathrm{Li}$ in stream water and groundwater vary between 14.5 and $40.0 \%$ o. This range is more than half that observed in rivers globally. The $\delta^{7} \mathrm{Li}$ of aqueous Li increases with increasing Li retention in secondary minerals, which is simulated using a box model that considers pore fluid advection to be the dominant transport process, silicate dissolution to be the source of Li to the pore fluid, and uptake of Li by kaolinite, Fe-
\end{abstract}


oxides, and interlayer sites of clays to be the sinks. The simulations suggest that only those deep groundwaters with $\delta^{7} \mathrm{Li}$ values of $\sim 15 \%$ are explainable as steady state values; those fluids with $\delta^{7}$ Li values $>18 \%$, especially near-surface waters, can only be explained as timedependent, transient signals in an evolving system. Lithium is highly retained in the residual solid phase during chemical weathering; however, bulk soils $(0.5 \pm 1.2 \%$ (1 SD)) and stream sediments $(0.3 \%)$ have similar, or higher, $\delta^{7} \mathrm{Li}$ compared to average bedrock $(-2.0 \%)$. This is attributed to preferential removal of clay particles from soils. Soil clays are isotopically depleted in ${ }^{7} \mathrm{Li}\left(\delta^{7} \mathrm{Li}\right.$ values down to $-5.2 \%$ ) compared to parental material, and $\delta^{7} \mathrm{Li}$ values correlate with soil Li concentration, soil $\mathrm{pH}$, and availability of exchangeable sites for $\mathrm{Li}$ as a function of landscape position (valley floor versus ridge top). The strong depletion of Li and clay minerals in soils compared to bedrock is attributed at least partly to loss of Li through export of fine-grained clay particles in subsurface water flow. This process might be enhanced as the upper weathering zone of this catchment is highly fractured due to former periglacial conditions. The Li isotopic composition of vegetation is similar to soil clay and both are distinct from mobile catchment water (in soil pore water, stream and groundwater). Extrapolating from this catchment means that subsurface particle loss from shales could be significant today and in the past, affecting isotopic signatures of soils and water. For example, clay transformations together with removal of clay particles before re-dissolution support weathering conditions that lead to a low aqueous Li flux but to high $\delta^{7}$ Li values in water.

\section{Introduction}

Chemical weathering of silicate minerals promotes secondary mineral formation and the release of aqueous cations and alkalinity to the ocean. These reactions are linked to the long-term carbon cycle by removing atmospheric $\mathrm{CO}_{2}$ through solubilization of silicate minerals and to the short-term cycle by supplying nutrients to facilitate biological activity. Both of these processes can sequester carbon in carbonates and organic matter in the marine sedimentary column. Therefore, weathering is a key process that regulates atmospheric $\mathrm{CO}_{2}$ over geological time scales (Walker et al., 1981; Berner et al., 1983; Kump et al., 2000). Over the Cenozoic, weathering fluxes and intensity have varied in ways that have impacted climate, atmospheric composition, and seawater chemistry, and these changes have been explored by seawater records of isotopes such as Sr and Os (e.g., Peucker-Ehrenbrink and Ravizza, 2000; Peucker-Ehrenbrink and Fiske, 2019) and more recently in records of beryllium isotopes 
$\left({ }^{10} \mathrm{Be} /{ }^{9} \mathrm{Be}\right)$ (Willenbring and von Blanckenburg, 2010; Wittmann et al., 2017; Valletta et al., 2018) and Li isotopes (Hall et al., 2005; Hathorne et al., 2006; Misra and Froelich, 2012; Dellinger et al., 2018; Roberts et al., 2018). For example, the seawater Li isotope curve shows an increase of about 9\%o during the Cenozoic to the modern $\delta^{7} \mathrm{Li}$ value of $31 \%$ (Misra and Fröhlich, 2012; Hathorne et al., 2006), which has engendered a debate over the primary controls on the $\mathrm{Li}$ isotopic composition of the continental weathering flux. Most interpretive studies focus on clay formation as a key mechanism controlling Li isotopic fractionation (Bouchez et al., 2013; Li and West, 2014; Wanner et al., 2014; Vigier and Godderis, 2015; Rugenstein et al., 2019). A few studies have also explored $\delta^{7} \mathrm{Li}$ in clastic sediment records and in stalagmites as a tracer of paleo weathering intensities on the glacial-interglacial time scale (Dosseto et al., 2015; Bastian et al., 2017; Dellinger et al., 2017; Pogge von Strandmann et al., 2017a).

Lithium isotopic fractionation occurs during clay formation and adsorption processes, both of which favor the incorporation of the light nuclide (Huh et al., 1998; Zhang et al., 1998; Pistiner and Henderson, 2003; Williams and Hervig, 2005; Pogge von Strandmann et al., 2006; Vigier et al., 2008; Teng et al., 2010; Wimpenny et al., 2010, 2015; Hindshaw et al., 2019a; Li and Liu, 2020). Such reactions have been interpreted to generate variable $\delta^{7} \mathrm{Li}_{\text {aq }}$ values in aqueous $\mathrm{Li}$ in rivers that range from 1.3 to $43.7 \%$ (high compared to bedrock). The global average for large rivers is about 23\% (Huh et al., 1998; Hindshaw et al., 2019a). The difference in $\mathrm{Li}$ isotopic composition between aqueous $\mathrm{Li}$ in river water and bedrock, $\Delta^{7} \mathrm{Li}_{\text {aq-rock, }}$, is thought to be controlled by the balance between Li released by mineral dissolution and Li uptake by secondary mineral formation (Bouchez et al., 2013).

Lithium isotopic systematics thus have strong implications for understanding the partitioning of minerals into those that solubilize during chemical weathering versus less soluble minerals that are removed by physical erosion at the land surface. These two fluxes referred to here as $\mathrm{W}$ (chemical weathering flux) and $\mathrm{E}$ (physical erosion flux) respectively can be summed to describe the denudation flux, D (Riebe et al., 2017). Lithium isotopes are considered useful in understanding the partitioning into $\mathrm{W}$ and $\mathrm{E}$ because $\Delta^{7} \mathrm{Li}_{\text {aq-rock }}$ is sensitive to the weathering intensity (=W/D). Perhaps most importantly, a study on the Amazon basin together with data from other large river systems elucidated a bell-shaped relationship between $\Delta^{7} \mathrm{Li}_{\text {aq-rock }}$ and weathering intensity (see Fig. 1 for a schematic) that was attributed to 
changes in the weathering regime (Dellinger et al., 2015). Kinetically-limited systems were thought to be characterized by high $\mathrm{D}$ (caused by high $\mathrm{E}$ ) and low W/D. Under such conditions, typically reflected by highlands, mineral dissolution prevails over secondary mineral formation and systems are characterized by a high aqueous Li flux and little isotopic fractionation. These conditions result in low $\delta^{7} \mathrm{Li}_{\mathrm{aq}}$ values in river water that are closer to bedrock values (e.g., Kisakürek et al., 2005). A somewhat similar situation occurs for supply-limited systems that prevail in lowlands (e.g., old shield terrains) where W/D is high due to low E (e.g., Clergue et al., 2015). As in the case above, mineral dissolution dominates over secondary mineral formation because clay minerals start to dissolve, resulting in relatively low $\delta^{7} \mathrm{Li}_{\text {aq }}$ values in river water and a low aqueous Li flux. A different situation exists for mid-range W/D, typically occurring in floodplains: a high rate of secondary mineral formation promotes high $\delta^{7} \mathrm{Li}_{\mathrm{aq}}$ values in river water but a low aqueous Li flux (Bagard et al., 2015; Pogge von Strandmann et al., 2017b).

To advance Li isotopes as a proxy for present-day and paleo-weathering processes, and to understand how isotopic fractionation relates to $W$ and $E$, it is essential to elucidate the controls of $\mathrm{Li}$ isotopic fractionation for aqueous and particulate Li riverine export. Given that two thirds of the exposed continents are today covered by sedimentary rocks that contain a low fraction of primary minerals other than quartz (Holland, 1978; Gaillardet et al., 1999; Hartmann and Moosdorf, 2012; Dellinger et al., 2014), we present Li isotopic results for a shale-underlain watershed. The weathering of shale in particular is important because this lithology comprises more than half of sedimentary rocks while containing a high abundance of Li-rich clay mineral phases (Teng et al., 2004).

At its most simple, shale is dominated by clay and quartz, with variable but generally less abundant feldspar, carbonate minerals, iron oxides, and lithic fragments. In the catchment investigated here (Shale Hills), Li release during weathering is dominated by clay mineral reactions, as feldspar is low in abundance, and quartz dissolution rates are extremely slow as in most canonical shales (Jin et al., 2010). What is not as well known, however, is how much shale is lost to chemical weathering versus physical erosion (i.e. the weathering intensity $W / D)$. Accordingly, this study fills in a critical gap in knowledge regarding Li isotopic fractionation associated with shale weathering. We investigate Li isotopic systematics associated with the weathering of Silurian gray shale at Shale Hills which is part of the 
Susquehanna Shale Hills Critical Zone Observatory (SSHCZO), U.S.A. We report the Li isotopic compositions and Li concentrations of soils and stream sediments, as well as stream water, soil water, and groundwater, and relate the effective isotopic fractionation observed in the system to specific processes; further, we quantify aqueous and particulate Li fluxes associated with shale weathering at the watershed scale.

\section{Field Site and Sample Descriptions}

The SSHCZO (Fig. 2) is part of a network of Critical Zone Observatories (CZO) established in the U.S.A. and proliferating worldwide to investigate the interaction of geochemical, geomorphological, hydrological, and biological processes in the weathering zone over different climatic conditions, tectonic settings, and lithologies (e.g., Brantley et al., 2018). The earliest focus site in the SSHCZO was Shale Hills, a V-shaped forested catchment, with a first-order ephemeral stream. Shale Hills covers an area of about $0.08 \mathrm{~km}^{2}$ in the northern part of the Appalachian Mountains in the central part of the state of Pennsylvania (USA). It is a well-characterized system (Brantley et al., 2018), as previous studies provide extensive data sets from field monitoring, elemental and isotopic measurements, and mineralogical investigations as well as abundant constraints developed from modelling (Lynch and Corbett, 1985; Lin et al., 2006; Qu and Duffy, 2007; Ma et al., 2010, 2011a, b, 2013, 2014, 2015; Jin et al., 2011; Jin and Brantley, 2011; Yesavage et al., 2012; Thomas et al., 2013; West et al., 2013; 2014; Noireaux et al., 2014, in press; Shi et al., 2014; Sullivan et al., 2016a; Herndon et al., 2018). Shale Hills is also one of a handful of watersheds where multiple isotopes have been measured on samples from identical locations, offering unparalleled capacity to test isotopic systematics as well as weathering processes (Sullivan et al., 2016b).

The study region is characterized by a humid-temperate climate, with an average annual precipitation of $102 \mathrm{~cm} \mathrm{y}^{-1}$ and a mean annual temperature of $10.1^{\circ} \mathrm{C}$ (based on a 30year record, NOAA, 2017). Stream discharge is high (ca. $0.05 \mathrm{~m}^{3} \mathrm{~s}^{-1}$ ) during snowmelt in spring and storm events in summer and fall, whereas the stream during the generally dry summer is more strongly affected by groundwater inflow (Jin et al., 2011; Kuntz et al., 2011; Thomas et al., 2013; Sullivan et al., 2016a). The stream goes dry in late summer and early autumn except for large storms during those dry months. Almost $90 \%$ of the water that enters the catchment and is not lost to evapotranspiration leaves as interflow, defined here to be shallow 
groundwater that flows downslope along transiently perched water tables into the stream (Sullivan et al., 2016a). The rest of the water leaves through infiltration to deep, regional groundwater that flows out of the catchment in the subsurface, sometimes entering the stream near the outlet.

The catchment is developed on the Silurian Rose Hill Formation in the Clinton Group and comprises mainly gray shales with minor carbonate and increasing carbonate and sandy layers toward the catchment outlet (Lynch and Corbett, 1985; Sullivan et al, 2016a; Brantley et al., 2018). The region is relatively undeveloped and largely pristine, and is covered by a mixed forest impacted by previous clear-cuts (most recent logging occurred in the 1930s) and minor impacts from regional eolian industrial pollution (Lin et al., 2006; Herndon and Brantley, 2011; Ma et al., 2014).

At Shale Hills, weathering takes place in reaction fronts from the depth of the groundwater table in bedrock up to the soil zone (Brantley et al., 2013). Chemical weathering of clays and feldspars is kinetically-limited (Gu et al., 2020). In contrast, weathering of pyrite and carbonate occurs rapidly and these minerals are not exposed at the land surface (Gu et al., 2020). Such mineral weathering has been shown to be localized in several reaction fronts that initiate at various depths (Fig. 3a) : 1) pyrite is completely depleted in soils and weathered rock by oxidative dissolution down to tens of meters depth under the ridges and $\sim 6 \mathrm{~m}$ under the valley floor; 2 ) carbonate is completely removed down to tens of meters depth under the ridges and to $2 \mathrm{~m}$ beneath the valley; 3 ) chlorite weathering generally initiates at the same depths as pyrite oxidation and continues upward to the soil zone; 4) plagioclase is depleted by weathering down to 5 or $6 \mathrm{~m}$; 5 ) illite mineral dissolution initiates at approximately the depth that the weathered rock disaggregates into soil, i.e., above about 1-2 $\mathrm{m}$ depth depending upon landscape position (Jin et al., 2010, 2011; Brantley et al., 2013; Sullivan et al., 2016a). The best approximation to the parental shale composition is derived from samples from deep cores of the bedrock. However, the weathered rock (referred to at the SSHCZO as "saprock") above the pyrite and carbonate weathering fronts retain most of the physical attributes of pristine bedrock. The typical saprock composition is 58 wt.\%o illite, 30 wt.\%o quartz, 11 wt.\%o "chlorite" (chlorite-like minerals which includes chlorite, vermiculite, and hydroxy-interlayered vermiculite (HIV)), and trace amounts of both feldspar (plagioclase and alkali-feldspar) and Fe-oxides (Jin et al., 2010; Jin and Brantley, 2011). The deep weathering 
associated with the pyrite and carbonate has little effect on the Li chemistry because the $\mathrm{Li}$ concentration in carbonates and pyrite is very low compared to silicate minerals; in addition, although chlorite weathering initiates under the ridges upon oxidative weathering of pyrite, the extent of "chlorite" weathering in the saprock remains exceedingly small (Gu et al., 2020).

Bulk soils in Shale Hills are affected by the mineralogy of parental material but contain organic matter and as much as 3 wt. \% kaolinite and are depleted in illite and "chlorite". Weathering of the carbonate-depleted saprock has been summarized by the following mineral transformations: 1) plagioclase $\rightarrow$ kaolinite, 2) illite $\rightarrow$ vermiculite, 3) chlorite $\rightarrow$ vermiculite, 4) vermiculite $\rightarrow$ HIV, 5) HIV $\rightarrow$ kaolinite + Fe-oxyhydroxide, and 6) pyrite $\rightarrow$ Fe-oxyhydroxide (Jin et al., 2010). Mass balance calculations using the mass transfer coefficient $\tau$ show that 20 to $50 \%$ of many elements have been lost from the soils as solutes whereas the other fraction is lost as micron-sized particles from throughout the soil column and from the subsurface saprock (e.g., Jin et al., 2010; Hasenmueller et al., 2017; Kim et al. 2018, 2019; Bern and Yesavage, 2018, 2019). The soil system at the catchment scale is approaching a steady state after the Last Glacial Maximum: the regolith production rate $\approx$ rate of physical erosive removal of soil within error, at least at the ridgetops. Values of both these rates have been summarized based on $\mathrm{U}$ disequilibrium and ${ }^{10} \mathrm{Be}$ concentrations (West et al., 2011, 2014; $\mathrm{Ma}$ et al., 2010, 2013). While the rates of these two processes are equal within a factor of 2 , some sediments are still retained in the catchment especially on the southern side toward the valley as the catchment appears to be moving toward a new steady state after the Last Glacial Maximum when the catchment experienced periglacial conditions.

Sample material for this study, further described below or in published papers, includes the major Li reservoirs in the catchment: bedrock, soils, stream sediments, groundwater, soil water, stream water and vegetation. The vegetation is represented by a composite leaf litter sample collected at several leaf litter traps distributed in the catchment (Herndon et al., 2015; Smith et al., 2017). Lithium concentration and Li isotopic composition of rock and soils were analyzed on well-investigated archived samples (sampling described in Jin et al. (2010)) from deep cores (DC1 and DC2) and from soil profiles from the southern planar transect along the north-facing hillslope (Fig. 2). Mineral and chemical composition of these samples were reported previously (Jin et al., 2010; Sullivan et al., 2016a). 
Two samples were used to characterize the sediment carried by stream water: sample "Weir" consists of sediments that were trapped behind a weir box installed at the outlet of the stream and sample "SSL" refers to the suspended sediment load collected by filtering stream water $(20 \mathrm{~L})$ to remove particles larger than $0.45 \mu \mathrm{m}$. Sample "SSL" was collected the $26^{\text {th }}$ of May 2014 during the wet season during low discharge to obtain fine-grained suspended sediments rich in weathering products. Water samples include soil water from suction-cup lysimeters installed in nested sets at the southern planar transect (Jin et al., 2010), stream water, and groundwater from wells sampled between October 2013 and August 2014. Groundwater wells are described in detail by Sullivan et al. (2016a). Additional water samples were taken from Shaver's Creek, the stream into which the first-order stream at Shale Hills flows (Brantley et al., 2018).

\section{Methods}

\subsection{Field measurements and element concentration measurements}

Field parameters of water samples including $\mathrm{pH}$, temperature $(T)$, specific conductance (SPC), dissolved oxygen (DO), total dissolved solids (TDS) and oxidation reduction potential (ORP) were determined using a multi-parameter unit YSI Profession Series probe. All water samples including soil water from lysimeters were filtered using a Nalgene filter unit $(0.45 \mu \mathrm{m}$ Nylon filter). Cations including $\mathrm{Al}, \mathrm{Ca}, \mathrm{Fe}, \mathrm{K}, \mathrm{Mg}, \mathrm{Na}, \mathrm{Sr}, \mathrm{Mn}$, and $\mathrm{Si}$ were determined by inductively coupled plasma emission spectrometry (a Perkin-Elmer Optima 5300 ICP-AES). The analytical precision is about $\pm 3 \%$ for major elements and $\pm 10 \%$ for minor elements. Lithium concentrations were measured using a Thermo Fisher Scientific $X$ Series 2, quadrupole inductively coupled plasma mass spectrometer (ICP-MS) with a precision of $\pm 5 \%$. Precision was determined by long-term analyses of reference samples. The concentrations of the anions $\mathrm{Cl}^{-}, \mathrm{NO}_{3}{ }^{-}, \mathrm{PO}_{4}{ }^{3-}$, and $\mathrm{SO}_{4}{ }^{2-}$ were determined by ion chromatography (Dionex lon Chromatograph ICS-250). The dissolved organic carbon (DOC) content was determined by a total organic carbon (TOC) analyzer (Shimadzu TOC-VCPH). The chemical composition and the mineral composition of the investigated rock and soil samples are published in Jin et al. (2010). Major and minor elements for suspended sediments were determined by ICP-AES after digestion as described in section 3.2.1.. Lithium concentrations were determined on digested bedrock, soil, and river sediment samples by ICP-MS. All concentration measurements were 
performed at the Pennsylvania State University (U.S.A.) in the Laboratory for Metals and Isotopes in the Environment (LIME). The mineralogy of the suspended sediment load sample was investigated by X-ray diffractometry (XRD) (PANanalytical Empyrean X-Ray diffractometer) in the Material Characterization Laboratory (MCL) at the Pennsylvania State University (U.S.A.).

\subsection{Lithium isotope measurements}

\subsubsection{Sample preparation}

Between 100 and $300 \mathrm{mg}$ of powdered rock and bulk soil (size fraction $<2 \mathrm{~mm}$ ) were dissolved in a 1:3 mixture of concentrated $\mathrm{HNO}_{3}$ and $\mathrm{HF}$ in acid-cleaned Teflon vials on hotplates at $90^{\circ} \mathrm{C}$. After 24 hours, $1 \mathrm{ml} \mathrm{HClO}_{4}$ was added to the mixture that was subsequently dried down at $120^{\circ} \mathrm{C}$ to a volume of $\sim 1 \mathrm{ml}$. The vials were then capped and kept at $150^{\circ} \mathrm{C}$ overnight. After cooling, a mixture of concentrated HF and aqua regia was added to each vial and the closed vials were heated at $150^{\circ} \mathrm{C}$ overnight. Clear, particle-free solutions were finally evaporated at $150^{\circ} \mathrm{C}$ and subsequently fluxed with concentrated $\mathrm{HNO}_{3}$ at $90^{\circ} \mathrm{C}$ for $5 \mathrm{~h}$. MilliQ water $\left(18.3 \mathrm{M} \Omega\right.$ ) was added to each vial and the samples were heated at $90^{\circ} \mathrm{C}$ until solutions were clear and particle-free, at which point they were dried down completely. The mixed leaf litter sample was digested following the same steps after rinsing in MilliQ water and ultrasonication. Finally, samples were oxidized several times by adding and drying down a mixture of concentrated $\mathrm{HNO}_{3}$ and $\mathrm{H}_{2} \mathrm{O}_{2}$.

Filtered water samples were treated by evaporating sufficient volume in Teflon vials to obtain 100 to $200 \mathrm{ng} \mathrm{Li}$. Samples were then oxidized several times in a mixture of concentrated $\mathrm{HNO}_{3}$ and $\mathrm{H}_{2} \mathrm{O}_{2}$ to remove organics prior to ion chromatographic purification of Li.

\subsubsection{Ion exchange chromatography and Li concentration measurements}

The method for Li purification was adapted from Rudnick et al. (2004) and involved a two-stage cation exchange chromatographic procedure. Columns (BioRad Poly-Prep Chromatography Columns) were filled with pre-cleaned Biorad resin $\mathrm{AG}^{\circledR} 50 \mathrm{~W}-\mathrm{X} 12$ resin (100200 mesh size) for both purification steps. To eliminate major elements, samples were loaded onto columns in $1.5 \mathrm{ml} 0.15 \mathrm{M} \mathrm{HCl}$ and eluted with $30 \mathrm{ml} 0.15 \mathrm{M} \mathrm{HCl}$. The collected fraction was then evaporated and re-dissolved in $1 \mathrm{ml} 0.15 \mathrm{M} \mathrm{HCl}$ prior to loading on the second 
column, whose purpose was to separate Li from $\mathrm{Na}$. The Li fraction was eluted with $16 \mathrm{ml}$ of a mixture of $30 \%$ ethanol and $0.5 \mathrm{M} \mathrm{HCl}$. Following Li elution, matrix elements were eluted by $10 \mathrm{ml}$ of $6 \mathrm{M} \mathrm{HCl}$ and $10 \mathrm{ml}$ MilliQ water. The resin was cleaned using $2.5 \mathrm{M} \mathrm{HNO}_{3}, 6 \mathrm{M} \mathrm{HCl}$ and MilliQ water before columns were prepared for the next sample set.

The purity and yield of Li were checked by ICP-MS after column separation. Lithium concentrations were measured in both pre- and post-chromatography aliquots, and for the column cut collected after the Li cut from the second column. Yields were generally $>95 \%$, and the cut collected after the Li cut contained $<3 \%$ of the total Li. A column yield of close to $100 \%$ is critical as Li isotopes fractionate significantly during exchange chromatography. To ensure purification, the post-chromatography Li fraction was analyzed for major cations, including $\mathrm{Na}, \mathrm{K}, \mathrm{Mg}, \mathrm{Fe}, \mathrm{Ca}$ and $\mathrm{Al}$. The ratios of major elements to Li were $\leq 2$. Samples with higher ratios, which occurred sporadically for $\mathrm{Na} / \mathrm{Li}$, were excluded from isotope analysis to ensure accurate results. Several rock standards, including AGV-2, RGM-1 and BCR-1 were digested, purified, and analyzed several times during the course of this study. The procedural blank, which was determined for each sample set and included all steps from digestion to ion exchange chromatography, was typical $<0.1 \mathrm{ng}$ of Li $(<0.1 \%$ of sample Li).

\subsubsection{Li isotope analyses}

Lithium isotope ratios were measured on a ThermoFisher Scientific NeptunePlus multicollector ICP-MS (MC-ICP-MS) at the Pennsylvania State University's Metal Isotope Laboratory (MIL). All analyses were performed in low resolution mode $(\mathrm{m} / \Delta \mathrm{m}>2000,5 \%)$ using a jet cone and a regular $\mathrm{H}$-skimmer cone under dry plasma conditions (using an ESI APEX desolvation system; uptake rate $\sim 120 \mu \mathrm{l} / \mathrm{min})$. Standard and purified samples were measured in matching matrices of $0.3 \mathrm{M} \mathrm{HNO}_{3}$, typically at $30 \mathrm{ppb} \mathrm{Li}$, that resulted in signal intensities between 7 and $10 \mathrm{~V}$ for ${ }^{7} \mathrm{Li}$ on a Faraday cup equipped with a $10^{11} \Omega$ resistor.

We applied a standard-sample-bracketing technique to correct for the instrumental mass bias and drift, and blank measurements were done just before and after each standard and sample. Standards and samples were measured for 25 cycles with an integration time of $4 \mathrm{~s}$, whereas blank analyses (acid matrix only) consisted of 10 cycles integrated over $4 \mathrm{~s}$. The typical Li background contributed less than $1 \%$ to sample (or standard) signal intensity. The take-up time was $180 \mathrm{~s}$ before the start of the measurement, and the wash-out time was 270 
s. Each sample was analyzed a minimum of two times in at least two separate analytical sessions and were corrected for the Li background offline. All Li isotope ratios are reported in standard delta notation relative to the reference material LSVEC in permil units (\%o):

$$
\delta^{7} L i=\left(\frac{{ }^{7} L i /{ }^{6} L i_{\text {Sample }}}{{ }^{7} L i /{ }^{6} i_{L S V E C}}\right) * 1000
$$

Frequent measurements of the Li in-house standard AA (Li Alfa Aeser solution) were conducted, yielding $\delta^{7} \mathrm{Li}$ values of $80.6 \pm 0.9 \%$ o (2SD, $\mathrm{n}=37$ ) over the period of this study. Analyzed rock standards reveal $\delta^{7} \mathrm{Li}$ values, which are identical within uncertainties to previous published data (see overview in GeoReM database; Jochum et al., (2005)): BCR-1 (basalt) gives $2.2 \pm 1.1 \%$ o (2SD, $n=3$ ) (published values range between 2.0 and 3.0\%o giving an average of $2.4 \pm 0.7 \%$ o $2 \mathrm{SD}, \mathrm{n}=11$ ), RGM-1 (rhyolite) gives $3.3 \pm 1.6 \%$ o (2SD, $\mathrm{n}=3$ ) (published values are $2.6 \%$ and $5.7 \%$ ) and two independent digestion and separation procedures for AGV-2 (andesite) gives $\delta^{7} \mathrm{Li}$ of $6.44 \pm 1.4 \%$ o (2SD, $\left.\mathrm{n}=4\right)$ and $\delta^{7} \mathrm{Li}$ of $6.00 \pm 2.2 \%$ o (2SD, $\mathrm{n}=2$ ) (published values range between 5.6 and $8.1 \%$ giving an average of $7.2 \pm 1.7 \%$ o $2 \mathrm{SD}, \mathrm{n}=9$ ).

In addition, we obtained $\delta^{56} \mathrm{Fe}$ and $\delta^{26} \mathrm{Mg}$ values for the suspended sediment load sample "SSL" following the methods described in Mansor and Fantle (2019) and Chanda and Fantle (2017), respectively.

\section{Results}

\subsection{Water chemistry}

Sample locations, data from field measurements, and major and minor cation and anion geochemistry are summarized in Table 1 and are in agreement with previous studies. Detailed investigations of the major rock-forming elements dissolved in the soil water, groundwater and stream water are discussed elsewhere (Jin et al., 2011; Sullivan et al., 2016a).

\subsection{Chemical and mineralogical composition of suspended sediments}

The chemical composition of suspended stream sediment sample "SSL" is as follows: 21.0 wt\% $\mathrm{Al}_{2} \mathrm{O}_{3}, 0.4$ wt\% $\mathrm{CaO}, 7.7 w t \% \mathrm{Fe}_{2} \mathrm{O}_{3}(\mathrm{t}), 3.8$ wt\% $\mathrm{K}_{2} \mathrm{O}, 1.3$ wt\% $\mathrm{MgO}, 0.7$ wt\% $\mathrm{TiO}_{2}, 132$ ppm Li and 100 ppm Zr. The silicon content was not determined. X-ray diffraction reveals 
17.1\% quartz, $22.8 \%$ kaolinite, $52.8 \%$ illite, and $7.3 \%$ chlorite-like minerals including chlorite, vermiculite and HIV (Fig. 4). The concentration of the suspended sediment sample "SSL" in the stream water was $5 \mathrm{mg} \mathrm{L}^{-1}$ at the time of sampling.

\subsection{Li concentration and isotopic composition}

Lithium isotopic data and concentrations are presented in Table 1 and 2 together with an overview in Fig. 3. Shale samples from deep boreholes $(n=5)$ show little variability in Li concentration (83 \pm 3 ppm Li, 1 SD) with one exception from shallow depth (sample DC1-8 from depth interval 1.1 to $1.2 \mathrm{~m}$ in well DC1 has $103 \mathrm{ppm}$ ). The Li isotopic compositions of these deep shale samples $(n=3)$ show a narrow range in $\delta^{7} \mathrm{Li}$ with values between $-1.6 \%$ and 0.4\%o. Compared to shale, soil samples exhibit a lower Li content, i.e., between 38 and 91 ppm, but similar $\delta^{7} \mathrm{Li}$ values, between -1.1 and $2.2 \%$. Streambed and suspended sediments (samples "Weir" and "SSL") reveal a Li content of 78 and $132 \mathrm{ppm}$, respectively and $\delta^{7} \mathrm{Li}$ values of 0.8 and $-0.3 \%$, respectively. Lithium content of the composite leaf litter sample was very low, $150 \mathrm{ppb}$, and yielded a $\delta^{7} \mathrm{Li}$ value of $-2.6 \%$. Compared to the bedrock, soils and stream sediments, all investigated water samples are enriched in ${ }^{7} \mathrm{Li}$ with aqueous $\delta^{7} \mathrm{Li}\left(\delta^{7} \mathrm{Li}_{\mathrm{aq}}\right)$ values ranging between 14.5 and $40.0 \%$ with lower values for most groundwater samples. Aqueous $\mathrm{Li}$ concentration ([Li $]_{\mathrm{aq}}$ ) of groundwater ranges from 0.59 to $0.86 \mu \mathrm{mol} \mathrm{L}^{-1}$ for deeper groundwater (CZMW1 and well\#6) and from 0.10 to $0.17 \mu \mathrm{mol} \mathrm{L}^{-1}$ for shallower groundwater (CZMW6 and well \#11), respectively. Water from the soil zone (soil water) and the headwater

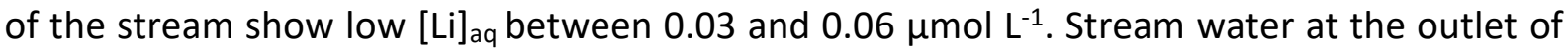
the catchment and water from Shaver's Creek reveal [Li $]_{\text {aq }}$ between 0.05 and $0.12 \mu \mathrm{mol} \mathrm{L}^{-1}$. In addition, we determined $\delta^{56} \mathrm{Fe}$ and $\delta^{26} \mathrm{Mg}$ values for the suspended stream sediment sample SSL, which are $0.10 \%$ and $0.36 \%$, respectively.

\section{Discussion}

The objective of this study is to constrain the dominant controls on $\mathrm{Li}$ isotopic fractionation and on Li elemental chemistry during shale weathering. The results, which are discussed in detail below, suggest that Li cycling and isotopic fractionation during shale weathering are dominated by clay transformations. The primary observation is that aqueous Li released from the shale catchment under consideration is isotopically fractionated at the watershed scale relative to bedrock, exhibiting a significant range in $\delta^{7} \mathrm{Li}_{\text {aq }}$ from $14.5 \%$ o to 
$39.4 \%$. In fact, the range of $\delta^{7} \mathrm{Li}_{\text {aq }}$ values in this small catchment is more than half of the variability measured in rivers globally ( $1 \%$ o to $44 \%$ o with a weighted average of $~ 23 \%$; Huh et al., 1998; Hindshaw et al., 2019a). In contrast, the isotopic compositions of soils and stream sediments are similar to that of the bedrock.

The following discussion focuses on the role of clay transformation processes in affecting the $\mathrm{Li}$ isotopic composition of both surface and groundwater at Shale Hills, emphasizing the retention of $\mathrm{Li}$ in the solid weathering products in controlling the $\delta^{7} \mathrm{Li}$ of both aqueous $\mathrm{Li}$ and $\mathrm{Li}$ in secondary minerals. Mass balance approaches are used to quantify $\mathrm{Li}$ elemental depletion at the catchment scale via aqueous and particle export driven by chemical and erosional weathering processes. Ultimately, we propose that much of the $\mathrm{Li}$ is lost as subsurface fluxes of clay particles at Shale Hills (Jin et al., 2010; Bern and Yesavage, 2018; 2019; Kim et al., 2018; 2019).

\subsection{Mechanistic controls on the Li isotopic composition of aqueous Li}

We sampled the first-order stream that drains out of Shale Hills (catchment size 0.08 $\mathrm{km}^{2}$ ) and the creek into which it flows (Shaver's Creek, catchment size $165 \mathrm{~km}^{2}$ (Fig 2)). The water chemistry and $\delta^{7} \mathrm{Li}_{\text {aq }}$ in Shaver's Creek match those of stream and shallow groundwater (Fig. 6, 7) for Shale Hills. In this section we seek to understand why we observe such a large range in $\delta^{7} \mathrm{Li}_{\text {aq }}$ in water samples.

Interaction of silicate minerals with water is generally considered to control Li isotopic fractionation and $\delta^{7} \mathrm{Li}_{\mathrm{aq}}$, as biological effects are negligible (Lemarchand et al., 2010; Clergue et al., 2015). Clay minerals, which are abundant in shales, have relatively high Li concentrations ( $100 \mathrm{ppm}$ ) and can be reactive during weathering (Teng et al., 2004; Chan and Hein, 2007; Jin et al., 2010). Other silicates in shale contain little Li, are low in abundance (such as feldspar), or are highly resistant to weathering (such as quartz).

Several studies have shown that isotopic fractionation between aqueous $\mathrm{Li}$ and secondary minerals depends primarily on the site of Li within the structure rather than on mineral composition (Pistiner and Henderson, 2003; Williams and Hervig, 2005; Chan and Hein, 2007; Vigier et al., 2008; Wimpenny et al., 2015; Fairén et al., 2015; Dupuis et al., 2017; Hindshaw et al., 2019a; Li and Liu, 2020). Recently, an experimental study by Hindshaw et al. 
(2019a) investigated isotopic fractionation between a Mg-rich smectite (2:1 layer silicate) and aqueous $\mathrm{Li}$ in detail and disclosed specific isotope fractionation factors ( $\Delta^{7} \mathrm{Li}_{\text {solid-aq }}$ ) associated with three different bonding environments of $\mathrm{Li}$ in clay minerals: 1) $-21.5 \%$ o for structurally bound, strong inner-sphere Li complexes at octahedral sites, 2) - $0.2 \%$ for Li as weak outersphere complexes (i.e. as exchangeable $\mathrm{Li}$ at interlayer sites or at adsorption sites on clay mineral surfaces) and 3) $+15.0 \%$ (with a large uncertainty) for the small amounts of $\mathrm{Li}$ occupying the cavities in tetrahedral sites that provide bonding similar to octahedral sites. Because of the large uncertainty of the degree of fractionation and the small amount Li at this bonding site, we will not further discuss \#3. Remarkably, the large fractionation identified in $\# 1$ is also observed for hydrated Li adsorption on Fe-oxides ( $\Delta^{7} \mathrm{Li}_{\mathrm{Fe} \text {-oxides-aq }} \approx-20 \%$ o) (Pistiner and Henderson, 2003; Chan and Hein, 2007; Wimpenny et al., 2015; Fairén et al., 2015). This is likely because such adsorption forms strong bidentate inner-sphere complexes with terminal oxygen ions. A recent experimental study suggests that both types of Li sorption, \#1 and \#2, are important on kaolinite surfaces leading to an intermediate fractionation factor $\left(\Delta^{7} \mathrm{Li}_{\text {kaolinite- }}\right.$ aq $\approx-8 \%$; Li and Liu, 2020).

At Shale Hills, many of these reactions could occur, albeit associated with distinct reaction fronts within the weathering zone. Specifically, groundwater elemental and isotopic compositions are affected by reaction fronts that vary in depth from oxidative weathering of chlorite to form vermiculite and Fe-oxides and of pyrite to form Fe-oxides, dissolution of carbonates, and plagioclase dissolution followed by kaolinite formation (e.g., Brantley et al., 2013; Fig. 3a, Fig. 5). A significant contribution to aqueous Li from carbonate dissolution is unlikely because of the low Li concentration in carbonate ( $~ 5 \mathrm{ppm})$ and the low abundance of $\mathrm{CaCO}_{3}$ in the shale bedrock ( $<10 \mathrm{wt} \%$; Jin et al., 2010) compared to clay minerals ( 100 ppm Li and 70 wt\%, respectively). In addition, a high contribution from carbonate dissolution would promote low $\mathrm{Li} / \mathrm{Ca}$ ratios and high $\delta^{7} \mathrm{Li}_{\text {aq }}$ values in groundwater because carbonates carry a seawater-like Li isotopic composition $\left(\delta^{7} \mathrm{Li}_{\text {seawater }}=30.8 \%\right.$; Marriott et al., 2004; Rosner et al., 2007; Lechler et al., 2015; Pogge von Strandmann et al., 2013).

If carbonates are not important in the Li system at Shale Hills, then Li mobilization is likely controlled by silicate weathering. In the watershed, chlorite weathers to vermiculite and then eventually precipitates kaolinite and Fe-oxide (Fig. 5). In chlorite, a "2:1:1" clay mineral with a low cation exchange capacity, Li mainly occupies octahedral sites. Transformation to 
the "2:1" clay mineral vermiculite involves the preferential dissolution of weaker Mg-rich octahedral layers, i. e. "brucite" layers, leading to the release of $\mathrm{Fe}$ and $\mathrm{Mg}$ together with $\mathrm{Li}$ and a slight loss of Al (Wilson, 2004). Lithium release during such mineral dissolution is likely not associated with isotopic fractionation because mineral dissolution generally does not cause fractionation (Pistiner and Henderson, 2003; Wimpenny et al., 2010; Verney-Carron et al., 2011). Lithium can also associate with vermiculite because it has a higher cation exchange capacity (Fig. 5) than chlorite. However, exchange between hydrated Al and Mg and Li in the interlayer sites as outer-sphere complexes does not cause isotopic fractionation because the bonding is weak (Hindshaw et al., 2019a). Thus, even though chlorite oxidation is a dominant silicate weathering process in Shale Hills, it is unlikely to control the high $\delta^{7} \mathrm{Li}_{\text {aq }}$ values observed in groundwater.

In contrast to vermiculitization of chlorite, the eventual formation of Fe-oxide and kaolinite as chlorite weathering proceeds may lead to high $\delta^{7} \mathrm{Li}_{\text {aq }}$ values. This is because adsorption of hydrated $\mathrm{Li}$ onto Fe-oxide and kaolinite is associated with strong isotopic fractionation ( $\Delta^{7} \mathrm{Li}_{\text {Fe-oxide-aq }} \approx-20 \%$; $\Delta^{7} \mathrm{Li}_{\text {Kaolinite -aq }} \approx$ - 8\%; Wimpenny et al. 2010; Li and Liu, 2020) (Fig. 5). Iron-oxides occur as a product of chlorite weathering and pyrite oxidation at almost all depths where these reactions have commenced at Shale Hills (Jin et al., 2010; Sullivan et al., 2016a; Gu et al., 2020) and could thus play a prominent role for Li isotopic fractionation in almost all waters. On the other hand, Li fractionation caused by association with kaolinite likely only becomes a prominent reaction in shallow groundwater (interflow) because kaolinite is generally only observed in the upper 5-8 m or so of the subsurface (Brantley et al., 2013). Given these considerations, the only major chemical reactions that fractionate $\mathrm{Li}$ isotopes in this setting are adsorption of hydrated Li on kaolinite at shallow depths and Feoxyhydroxide mineral surfaces at even deeper depths. Notably, such newly formed secondary minerals are likely to be poorly crystalline with a small grain size, and this is likely to increase the number of potential sorption sites.

Overall, the water chemistry is consistent with these mineral reactions. In near-surface water from the soil and interflow zone, low $\mathrm{Li} / \mathrm{Mg}$, $\mathrm{Li} / \mathrm{Si}$ and $\mathrm{Li} / \mathrm{K}$ ratios and variable $\delta^{7} \mathrm{Li}_{\mathrm{aq}}$ values are in line with clay dissolution/transformation and the preferential uptake of Li by neoformed kaolinite or Fe-oxides (Fig, 6b, c, d). In contrast, deep groundwater generally shows higher $\mathrm{Li} / \mathrm{Mg}$, $\mathrm{Li} / \mathrm{Si}$ and $\mathrm{Li} / \mathrm{K}$ ratios and more stable $\delta^{7} \mathrm{Li}_{\text {aq }}$ values, consistent with ongoing clay 
transformation processes. In the following we examine how these weathering reactions and isotopic fractionation mechanisms are reflected in the Li isotopic composition and chemistry of aqueous Li at Shale Hills.

Typically, the Li isotopic composition and the Li/Na ratio in water samples show an inverse correlation (Fig. 6a). Given that $\mathrm{Na}$ is largely released from the ( $\mathrm{Na}, \mathrm{Ca}$ )-containing plagioclase feldspar in this watershed (Jin et al., 2010), it is also not surprising that there is a similar correlation for Li/Ca for stream and shallow interflow groundwater (Fig. 6e). Lithium has an affinity for uptake by secondary minerals whereas $\mathrm{Na}$ and $\mathrm{Ca}$ are more unreactive following release to solution. At Shale Hills, near-surface waters from the soil zone and interflow are characterized by highly variable $\delta^{7} \mathrm{Li}_{\text {aq }}$ values up to $39.4 \%$ and low $\mathrm{Li} / \mathrm{Na}$ ratios. These two characteristics also describe the stream waters because the stream is dominated by interflow water during most of the year (Jin and Brantley, 2011; Sullivan et al., 2016a). In contrast, deep groundwater has a longer residence time (up to 30 years; Sullivan et al, 2016a) and shows lower, less variable $\delta^{7} \mathrm{Li}_{\text {aq }}$ values and high $\mathrm{Li} / \mathrm{Na}$ (Fig. 6a).

Such patterns between Li isotopic composition and aqueous Li concentrations and residence time have been observed in other catchments and linked to formation of secondary minerals over time or to the kinetic- or supply-limited nature of the weathering system (Huh et al., 1998, 2001; Kisakürek et al., 2005; Vigier et al., 2009; Millot et al., 2010b; Pogge von Strandmann et al., 2006, 2014, 2017b; Dellinger et al., 2015; Liu et al., 2015). In large river systems such as the Amazon, Mackenzie, and Brahmaputra-Ganges basins, for example, low $\delta^{7} \mathrm{Li}_{\text {aq }}$ values are observed in supply-limited systems - i.e. systems where waters and solids in soil have long residence times that enable intensive interaction of water with primary and secondary silicate minerals - whereas high $\delta^{7} \mathrm{Li}_{\text {aq }}$ values are observed in kinetically-limited systems - i.e. systems where waters and solids in soil have relatively short residence times, which limits interaction (Millot et al., 2010b; Dellinger et al., 2015; Henchiri et al., 2016). The basic idea is that isotopic fractionation relative to bedrock is observed when the water-rock interaction times are long enough to permit Li uptake into secondary minerals but also short enough to prevent slow re-dissolution of those minerals. These conditions apply for Shale Hills which lies in the range of medium weathering intensities and represents the conditions in Figure 1 that lead to low aqueous Li flux but high values of $\delta^{7} \mathrm{Li}_{\mathrm{aq}}$. 
This relationship between Li concentration and isotopic composition can be quantified to test the hypothesis that $\mathrm{Li}$ adsorption at interlayer sites of clay minerals can affect aqueous Li concentrations but not Li isotopic composition while Li adsorption on new mineral surfaces (kaolinite and Fe-oxyhydoxide) can drive the isotopic fractionation of aqueous Li (Fig. 5). To do this, we estimate the proportion of Li remaining in solution relative to the Li incorporated into secondary minerals. Assuming that the initial $\mathrm{Li} / \mathrm{Na}$ ratio ( $\mathrm{Li} / \mathrm{Na}$ aq,init) of the fluid reflects that of the bedrock, and that $\mathrm{Na}$ behaves conservatively, the fraction of Li remaining in solution after secondary mineral formation, $f_{a q}$, can be estimated by considering the Li/Na ratio of the aqueous species $(\mathrm{Li} / \mathrm{Na})_{\text {aq }}$ relative to the ratio in the bedrock, $(\mathrm{Li} / \mathrm{Na})_{\text {rock }}$ (Fig. 7) (e.g., Millot et al., 2010b):

$$
f_{a q}=\frac{(L i / N a)_{a q,}}{(L i / N a)_{a q, \text { init }}} \approx \frac{(L i / N a)_{a q}}{(L i / N a)_{\text {rock }}}
$$

The equation is meant to describe chlorite reactions that take place over the same depths as plagioclase weathering, i.e., in the interflow zone from 0 to about $9 \mathrm{~m}$ depth. This generalized approach has been widely applied in various river studies (e.g., Gislason et al, 1996) and is therefore used here to provide an estimate for $f_{a q}$ that is comparable to those in the literature (where very little is known about subsurface reaction zones).

The values of $f_{a q}$ calculated at Shale Hills are low ( $\left.<20 \%\right)$, consistent with the inference that most $\mathrm{Li}$ is incorporated into secondary minerals. This overall high degree of Li retention in the solid phase correlates with the isotopic compositions of clays and stream sediments. It is also interesting to note that these ratios are consistent with global average riverine flux estimates for Li: $20 \%$ as aqueous and $80 \%$ as particulate flux, respectively (Vigier and Godderis, 2015). Finally, groundwater shows a tendency to a higher fraction of aqueous Li (up to 20\%) whereas stream and water from the soil zone reveal extremely low $f_{a q}(<5 \%)$. Thus, there is more retention of $\mathrm{Li}$ in solid phases during weathering in the shallow layers where both Feoxide and kaolinite are present. However, the relationship in $\delta^{7} \mathrm{Li}_{\text {aq }}-f_{\text {aq }}$ space is non-linear for the data from Shale Hills (Fig. 7), which has been also observed in other catchment studies including large river systems (e.g., Amazon, Ganges, Brahmaputra and Columbia Rivers) where data show similar non-linear trends (Kisakürek et al., 2005; Vigier et al., 2009; Pogge von Strandmann et al., 2006, 2010; Bagard et al., 2013; Dellinger et al., 2015; Liu et al., 2015). Most 
of the non-linear trends are reported for terrains where weathering is kinetically-limited (like Shale Hills).

Non-linear trends in $\delta^{7} \mathrm{Li}_{\text {aq }}$ are commonly assessed using simple Rayleigh distillation models (e.g., Bagard et al., 2015; Bouchez, 2013; Dellinger et al., 2015; Pogge von Strandmann et al., 2012; Pogge von Strandmann et al., 2017a) or in some cases by more complex reactive transport models (e.g., Liu et al., 2015; Lemarchand 2010). Here, we constructed a box model to explain, in particular, this non-linear behavior of $\delta^{7} \mathrm{Li}_{\text {aq }}$ values and compare the results later on with a simple Rayleigh distillation approach. The box model allowed us to examine the interplay between mineral dissolution, solute advection, and Li removal from pore fluid by secondary mineral formation. The model considers silicate dissolution as the only Li source and major secondary mineral formation processes as $\mathrm{Li}$ sinks including $\mathrm{Li}$ removal by vermiculite/HIV at interlayer sites, and kaolinite precipitation for near-surface water (stream and shallow groundwater) and Fe-oxide precipitation for deep groundwater (see model schematics in Fig. 8a, b). We assumed dissolving clays have an isotopic composition of $-2.5 \%$, and that dissolution does not fractionate Li isotopically; the dissolution rate was held constant at a value of $3.2 \cdot 10^{-7} \mu \mathrm{mol} \mathrm{Li} \mathrm{d}{ }^{-1}$ (based on mineral dissolution rates, specific surface areas, and molar masses of clays at Shale Hills; Jin et. al., 2010). The removal of Li by secondary minerals did fractionate isotopically $\left(\alpha_{\text {interlayer-aq }}=0.9998, \alpha_{\text {kaolinite-aq }}=0.992, \alpha_{\text {Fe-oxide-aq }}=0.980\right.$ (Wimpenny et al., 2010; Hindshaw et al., 2019a; Li and Liu, 2020), and the output fluxes were assumed to be first order with respect to Li pore fluid concentration (i.e., mass flux, $F=k^{*} N_{p f}$, see Fig. 8).

Because the rate constants are unknown, we ran a series of simulations (100 to 250 ) to steady state, while varying the rate constants over ranges (i.e., assuming uniform distribution) and sampling using a Sobol Sequence routine (see caption of Fig. 8 for details). Because we did not know the precise residence time of fluids, we also varied the residence time between 5 and 20 years. The result of this approach was the generation of steady state solution envelopes for a given model scenario in a $\delta^{7} \mathrm{Li}_{\mathrm{aq}}$-Li concentration space (Fig. 8a, b). Outside of this envelope, steady state solutions are not possible for a given scenario. A benefit of this approach is that it clearly illustrates endmember scenarios (e.g., dissolutiondominated, clay-sink dominated) and gives a general sense of the likelihood of a particular scenario occurring. 
The modeling suggests that in scenarios in which the sinks dominate (left hand side of Fig. $8 \mathrm{a}, \mathrm{b}), \delta^{7} \mathrm{Li}_{\mathrm{aq}}$ can vary quite widely but the steady state values do not surpass $\sim 18 \%$. Yet almost all the fluids measured at Shale Hills plot significantly above the steady-state envelopes. Thus, as long as the fractionation factors we assume are appropriate, the fluids measured at Shale Hills cannot reflect steady state.

Accordingly, we suggest that our $\delta^{7} \mathrm{Li}_{\mathrm{aq}}$ and $\mathrm{Li}$ concentration measurements reflect transient conditions in the sub-surface system, which is supported by time-dependent model trajectories (Fig. $8 \mathrm{c}$ and d). Amongst the parameters that determine the position of these trajectories in $\delta^{7} \mathrm{Li}_{\text {aq }}-\mathrm{Li}$ concentration space are the initial $\delta^{7} \mathrm{Li}_{\mathrm{aq}}$ and $\mathrm{Li}$ concentration of the fluid. For the trajectories shown here, we can explain deep groundwater and near-surface waters assuming an initial Li concentration of $\sim 2$ to $4 \mu \mathrm{M}$ and an initial $\delta^{7} \mathrm{Li}_{\text {aq }}$ value of $-2.5 \%$. Seen through this lens, deep groundwater can be explained as less evolved fluids whose differences are explained by changes in fluid residence time and modest differences in the relative importance of the oxide and clay sinks (Fig. 8c). By contrast, near-surface water with exceedingly high $\delta^{7} \mathrm{Li}$ values must be dominated by fractionation associated with kaolinite precipitation. Interestingly, these high $\delta^{7} \mathrm{Li}_{\text {aq }}$ are not the most evolved fluids in the system; if this framework is correct, those fluids with values closer to the steady state envelope are actually the most evolved.

Our interpretation is consistent with the seasonal variation in $\delta^{7} \mathrm{Li}_{\text {aq }}$; in the spring, lower $\delta^{7} \mathrm{Li}_{\text {aq }}$ values occur as a consequence of reduced secondary mineral formation (Giesler et al., 2000; Wilson, 2004; Andrews et al., 2011). In the summer, kaolinite precipitation increases (Sullivan et al., 2019), which generates high, variable $\delta^{7} \mathrm{Li}_{\text {aq }}$ values. By comparison, deep groundwater is more homogenous isotopically, is impacted to a lesser extent by secondary minerals (Fig. 7), and is generally less evolved compared to near-surface water. Increased $\delta^{7} \mathrm{Li}_{\text {aq }}$ values (e.g., in deep groundwater sampled at the stream outlet, CZMW1) are also compatible with previous suggestions that hydrological changes in flow pathways increase residence times of groundwaters during the summer (Sullivan et al., 2016). Overall, the box modeling supports the contention that the Li isotopic composition of stream and groundwater is impacted by significant retention of Li in the solid phase (Fig. 7). Interestingly, if our assumptions are valid, the model suggests that steady state conditions are rarely achieved in this system, even in groundwater that ostensibly has long residence times. 
Instead, $\delta^{7} \mathrm{Li}_{\text {aq }}$ is a time-dependent phenomenon that is controlled primarily by the relative rates of Li removal into secondary minerals.

\subsection{The loss of particulate $L i$ in the soil zone}

Measured $\delta^{7} \mathrm{Li}_{\text {soil }}$ values of bulk soil samples range between -0.6 and $2.2 \%$ with an average of $0.5 \pm 1.2 \%$ o ( $1 \mathrm{SD}$ ). These values are similar to but slightly higher than those of bedrock (average $\delta^{7} \mathrm{Li}_{\text {rock }}=-0.6 \%$ ) and are in the range of typical shales, which have a high proportion of structurally bound $\mathrm{Li}\left(\delta^{7} \mathrm{Li}\right.$ shale ranges between -4.1 and $4.3 \%$ ) (Teng et al., 2004; Romer and Meixner, 2014; Williams et al., 2015; Phan et al., 2016; Hindshaw et al., 2018).

The higher $\delta^{7} \mathrm{Li}_{\text {soil }}$ values compared to $\delta^{7} \mathrm{Li}_{\text {rock }}$ are surprising because chemical weathering is expected to drive weathering residuals to lower $\delta^{7} \mathrm{Li}$ values. However, the mineral composition of soil profiles show that secondary mineral phases are increasingly diluted with weathering resistant quartz moving upwards in the soil profile (Fig.4; Jin et al., 2010). Quartz differs significantly in Li isotopic composition $\left(\delta^{7} \mathrm{Li}_{\text {quartz }} \approx 30 \%\right.$; Sauzeat et al., 2015) compared to secondary minerals, explaining why the isotopic composition of bulk soils at Shale Hills moves toward high $\delta^{7} \mathrm{Li}_{\text {soil }}$ values toward the land surface. Using a simple mass balance approach for soils and suspended sediments and bedrock, we estimate the isotopic composition, $\delta^{7} \mathrm{Li}_{\text {clay, }}$ and the $\mathrm{Li}$ concentration, $[\mathrm{Li}]_{\text {clay, }}$ of the fraction containing clays and oxides. To do this, we use the relative mineral abundances $m$ (Jin et al., 2010) and the isotopic composition and $\mathrm{Li}$ concentration of bulk samples, $\delta^{7} \mathrm{Li}_{\text {bulk }}$ and $[\mathrm{Li}]_{\text {bulk, }}$, respectively (Table 2 ) while assuming the Li isotopic compositions and concentrations for quartz and feldspar are as compiled by Sauzeat et al. (2015), i.e., representative of the upper continental crust $\left(\delta^{7} \mathrm{Li}_{\text {quartz }}\right.$ $=30 \% ;[\mathrm{Li}]_{\text {quartz }}=10 \mathrm{ppm}$ and $\delta^{7} \mathrm{Li}_{\text {feldspar }}=2.5 \%$; $\left.[\mathrm{Li}]_{\text {feldspar }}=2 \mathrm{ppm}\right)$. The fraction of $\mathrm{Li}$ contributed from each mineral phase $\left(m_{L i, c l a y}, m_{L i, f e l d s p a r}\right.$ and $\left.m_{L i, q u a r t z}\right)$ is defined by the relative mineral abundance and the Li concentration of the mineral phase. The calculation was completed using Equations (4) and (5):

$$
\begin{aligned}
& {[\mathrm{Li}]_{\text {bulk }}=m_{\text {clay }}[\mathrm{Li}]_{\text {clay }}+m_{\text {quartz }}[\mathrm{Li}]_{\text {quartz }}+m_{\text {feldspar }}[\mathrm{Li}]_{\text {feldspar }}} \\
& \delta^{7} L i_{\text {bulk }}=m_{\text {Li,clay }} \delta^{7} L i_{\text {clay }}+m_{\text {Li,quatz }} \delta^{7} L i_{\text {quartz }}+m_{\text {Li,feldspar }} \delta^{7} L i_{\text {feldspar }}
\end{aligned}
$$


These calculations reveal average $\delta^{7} \mathrm{Li}_{\text {clay }}$ and $[\mathrm{Li}]_{\text {clay }}$ values of $-5.2 \%$ and $\sim 92 \mathrm{ppm}$, respectively, for ridge top soils, both lower than the values for the valley floor soils $\left(\delta^{7} \mathrm{Li}_{\text {clay }}\right.$ and [Li $]_{\text {clay }}$ are $-1.8 \%$ and $123 \mathrm{ppm}$, respectively) (Table 2 ). Thus, the valley floor clay fraction is similar to bedrock (average $\delta^{7} \mathrm{Li}_{\text {clay }}=-2.0 \%$; $[\mathrm{Li}]_{\text {clay }}=121 \mathrm{ppm}$ ) $($ Table 2, Fig. 9a) whereas the clay fraction of the ridgetop soil is comparatively depleted in the heavy nuclide. Below, we discuss Li depletion profiles in the soils, followed by a discussion in differences in $\delta^{7} \mathrm{Li}_{\text {clay }}$ and $[\mathrm{Li}]_{\text {clay }}$ as a function of hillslope position.

Elemental ratios in soil profiles and stream sediments are one way to quantify loss or gain of an element. Specifically, the loss or gain of Li relative to the source material can be quantified by calculating the non-dimensional mass transfer coefficient $\tau_{i, j}$ (Brimhall and Dietrich, 1987; Chadwick et al., 1990; Anderson et al., 2002):

$$
\tau_{i, j}=\frac{C_{j, w} C_{i, p}}{C_{j, p} C_{i, w}}-1
$$

This concept is based on the ratio of the concentrations $C$ of a mobile element $j$ and an immobile element $i$ defined for weathered material $w$ and unweathered parental material $p$. The element $j$ is depleted compared to the immobile element in weathered material compared to parental material for $\tau<0$ and enriched for $\tau>0$, e.g. by adding material to the weathering profile. There is neither depletion nor enrichment for $\tau=0$. The mobility of major elements relative to the source rock in Shale Hills soil profiles has been previously investigated (Jin et al., 2010; Kim et al., 2018), where Zr has been suggested as an adequate immobile element. Recently, it has been pointed out that much of the loss of major elements from Shale Hills soils at depths may be caused by loss of particles and not by loss of solutes (Kim et al., 2018). To investigate this, it has been proposed that another version of $\tau$ can be defined using $\mathrm{Al}$ as the immobile element because it is assumed to be largely retained in clay minerals (Jin et al., 2010; Hasenmueller et al., 2017; Kim et al., 2018). In effect, when $\tau_{z r, j}$ and $\tau_{A l, j}<0$, $\tau_{z r, j}$ can be thought of as the fractional loss of element $\mathrm{j}$ as both particles and solutes, while $\tau_{\mathrm{Al}, \mathrm{j}}$ can be thought of as the fractional loss of element $\mathrm{j}$ as solute alone.

Thus, values of $\tau_{\mathrm{Zr}, \mathrm{Li}}$ allow estimation of the total Li depletion in soil whereas $\tau_{\mathrm{Al}, \mathrm{Li}}$ can provide an estimate for the chemical weathering loss of $\mathrm{Li}$. The difference between $\tau_{\mathrm{Zr}, \mathrm{Li}}$ and $\tau_{\mathrm{Al}, \mathrm{Li}}$ provides an estimate of $\mathrm{Li}$ mobility via particle transport out of the soil profile 
(Hasenmueller et al., 2017; Kim et al., 2018). Although exact values are somewhat dependent on assumptions in the calculation related to immobility of $\mathrm{Zr}$ (Bern and Yesavage, 2018), we calculated $\tau_{Z r, L i}$ and $\tau_{\mathrm{Al}, \mathrm{Li}}$ based on the Li concentrations provided in Table 2 and the $\mathrm{Zr}$ and $\mathrm{Al}$ concentrations published in Jin et al. (2010). Soil profiles reveal a total loss of Li between 20 and $80 \%$ depending on soil position and sample depth (Fig. $9 \mathrm{~b})\left(\tau_{\mathrm{zr}, \mathrm{Li}}:-0.21\right.$ to -0.81$)$. However $\tau_{A l, L i}$ values indicate that only around $20 \%$ of the Li was lost as aqueous Li from the soils at the ridge top (average $\tau_{\mathrm{Al}, \mathrm{Li}}:-0.21$ ) whereas barely any chemical weathering loss is needed to explain the data for the valley floor (average $\tau_{\mathrm{Al}, \mathrm{Li}}:-0.03$ ) (Fig. 9c). The interpretation is that about $50 \%$ of $\mathrm{Li}$ is lost via particle export from within the profiles of the ridge top soils whereas up to $75 \%$ of the mobilized Li is lost by particles in the valley floor (Fig. 9d).

These calculations and observations lead to explanations for the observed pattern of isotopic fractionation and Li elemental depletion in soils within the catchment. Interestingly, the data for soils along the south planar transect show that $\delta^{7} \mathrm{Li}_{\text {clay }}$ correlates with [Li] clay, soil $\mathrm{pH}$, the ratio of Al to cation exchange capacity (CEC) (Jin et al., 2010), and $\tau_{\mathrm{Al}, \mathrm{Li}}$ values (Fig. 10). Specifically, higher soil pH values (> 4.5) are observed in lower elevation soils compared to ridge top soils ( $\mathrm{pH}<4.5$ ) (Jin et al., 2010). The low [Li]clay calculated in the ridge top soils may therefore be related to soil $\mathrm{pH}$. At low $\mathrm{pH}, \mathrm{Al}^{3+}$ becomes the dominant cation on exchangeable interlayer sites of vermiculite/HIV (high values of Al/CEC) (Jin et al., 2010). Thus the ridgetop soils have likely released $\mathrm{Mg}, \mathrm{Ca}$ and $\mathrm{Li}$ from exchange sites, leaving behind strongly bonded $\mathrm{Li}$ at octahedral sites that are enriched in the light nuclide (Hindshaw et al., 2019a), i.e., low $\delta^{7} \mathrm{Li}_{\text {clay }}$ values. In the higher $\mathrm{pH}$ valley soils, the lower value of $\mathrm{Al} / \mathrm{CEC}$ translates to a higher capacity for adsorption of $\mathrm{Mg}$ and $\mathrm{Ca}$ and $\mathrm{Li}$. This explains the higher [ $\mathrm{Li}]_{\text {clay }}$ in soil at the valley floor compared to those of the ridges. No isotopic fractionation is associated with Li uptake into interlayer sites (Hindshaw et al., 2019a), but adsorption of Li from isotopically fractionated soil water increases $\delta^{7} L_{\text {clay }}$ in soils. In summary, the availability of exchangeable interlayer sites for Li in vermiculite/HIV mainly controls $\delta^{7} \mathrm{Li}_{\text {clay }}$ of the soil clays at Shale Hills.

The same effect has been proposed for $\mathrm{Mg}$ isotopes at SSHCZO: $\delta^{26} \mathrm{Mg}$ of soils is impacted by Mg uptake from isotopically fractionated soil water into vermiculite/HIV (Ma et al., 2015). This process is also consistent with B isotope data of soils and soil water at Shale Hills (Noireaux et al, 2014; in press). This conformity is not surprising because $\mathrm{Mg}$, Li, and B favor similar bonding sites during clay formation. Remarkably, the isotopic compositions of 
water and bulk soil/soil clays are driven by distinct processes. Although kaolinite and Fe-oxide precipitation govern $\delta^{7} \mathrm{Li}_{\text {aq }}$, these processes have little influence on $\delta^{7} \mathrm{Li}_{\text {clay }}$ or on bulk soil isotopic composition because two effects make isotopic fractionation barely recognizable in the solid phase: i) the high affinity of Li to kaolinite and Fe-oxides and its nearly quantitative uptake from solution and ii) the low abundance of these mineral phases. Instead, the isotopic composition of soil clays is controlled by the availability of interlayer sites in the clay structure providing sites for uptake of isotopically heavy pore water. At the same time, however, bulk soil chemistry is dominated increasingly by weathering resistant quartz grains with positive $\delta^{7} \mathrm{Li}$ compared to parental rock as clay particles have been transported away (Jin et al., 2010). Similar to this observation, $\mathrm{Mg}$ and $\mathrm{B}$ isotopic compositions of bulk soils are also controlled by loss of clay particles with a distinct isotopic signature (Ma et al., 2015; Noireaux et al., 2014; in press).

In general, elemental depletion on the catchment-scale is controlled by both aqueous and particle transport through the subsurface. At the ridge top, $20 \%$ of Li has been lost as aqueous $\mathrm{Li}$ and $\sim 50 \%$ by subsurface particle transport (Fig. 9). Some of this material is moved downslope (both as aqueous $\mathrm{Li}$ and particles). In the valley floor, aqueous Li re-equilibrates with the ion exchange sites in the solid-phase (vermiculite/HIV), resulting in a net aqueous flux out of the valley floor soils that is near-zero ( $\tau_{\mathrm{Al}}$ Li close to zero; Fig. 9c). Depletion of $\mathrm{Li}$ occurs almost exclusively by particle transport from the valley floor $\left(\tau_{Z r, L i} \approx\left(\tau_{Z r, L i}-\tau_{A l}, \mathrm{Li}\right)\right.$; Fig. $9 b, d)$. Therefore, the soils retain most of the Li in the solid phase in the valley floor soils, only releasing a small fraction of Li-containing illite and kaolinite particles (Fig. 4 and 9). The extent of Li elemental depletion by particle export from the soils correlates with weathering duration (Ma et al., 2013) which suggest continuous particle loss with time (Fig. 11). However, the depletion by particles does not reach zero at time zero (Fig. 11) nor at the base of the soil zone (Fig. 9d), indicating that particle export also occurs below the soil zone in underlying bedrock as suggested by Kim et al. (2018).

These findings are in agreement with $\tau$ values of major elements in soil profiles and deep cores, geochemical investigations of mobile particles in groundwater and stream water (Lin et al., 2006; Jin et al., 2010; Yesavage et al., 2012; Bern and Yesavage, 2018; Kim et al., 2018) and the fact that U-series show no secular equilibrium at the base of soils (Ma et al., 2013). These studies suggest that micron-sized particles are transported in the subsurface 
along preferential water flow pathways through macro-pores as well as through fractured bedrock down to a depth of about 5 to 8 meters. Investigations of mobile particles from groundwater and stream water shows that these particles differ chemically and mineralogically from average bulk shale in that they have a higher proportion of illite (Kim et al., 2018). Therefore, depletion of Li via particle export is in agreement with the discovery by other researchers that subsurface erosion by selective clay particle mobilization in soil and weathering rock substantially contributes to element depletion and results in changes in the rock and soil chemistry at Shale Hills (Jin et al., 2010; Bern and Yesavage, 2018; Kim et al., 2018). Moreover, this finding of subsurface erosion of clay particles in shale might support conditions which promote maximum values of $\delta^{7} \mathrm{Li}_{\mathrm{aq}}$ in the relationship between weathering intensity and the degree of isotope fractionation of aqueous Li (Fig. 1) (Bouchez et al., 2013; Dellinger et al., 2015; Rugenstein et al., 2019). In other words, Shale Hills is a case where a high rate of secondary mineral formation followed by particle loss in the subsurface before re-dissolution results in a low aqueous $\mathrm{Li}$ flux with high $\delta^{7} \mathrm{Li}_{\mathrm{aq}}$ values. Shale Hills shows that shale-dominated landscapes operate like floodplains as shown in the figure 1.

\subsection{Aqueous and particulate export of Li in the catchment}

\subsubsection{Quantifying aqueous versus particulate export}

We can compare depletion fluxes of Li on the catchment-scale calculated from the soil profiles to mass balance estimates for the entire catchment. To do this we make the simplifying assumption that the rate of production of Li-containing regolith equals rate of loss of Li-containing regolith (Ma et al., 2010, 2013; West et al., 2013, 2014). Then, the particle flux $X_{L i, p a r t}$ can be estimated from the aqueous flux $X_{L i, a q}$ and the total Li flux out of the system which has to be equal to the Li flux from rock entering the weathering zone $X_{L i \text { rock }}$ at steady state (Fig. 12):

$$
X_{L i, p a r t}=X_{L i, r o c k}-X_{L i, a q}
$$

where $X_{L i}$, rock is calculated from the product of the area-weighted average soil production rate P of $31.9 \mathrm{~m} \mathrm{Myr}^{-1}$ (West et al., 2013, 2014), the rock density, $\rho_{\text {rock, }}$ of $2.6 \mathrm{~g} \mathrm{~cm}^{-3}$ (Jin et al., 2010), and the average Li concentration in bedrock [Li] rock of $83 \mathrm{ppm}$ :

$$
X_{\text {Li,rock }}=P \rho_{\text {rock }}[\text { Li }]_{\text {rock }}
$$


The aqueous flux $X_{L i, a q}$ consists of 1 ) the stream water flux assuming the annual average discharge $q_{\text {stream }}$ equals $32760 \mathrm{~m}^{3} \mathrm{y}^{-1}$ (average discharge from 2008 to 2015; Xiao et al., 2019) and a discharge-weighted average Li concentration in the stream $[L i]_{\text {stream }}$ of $0.07 \mu \mathrm{mol} \mathrm{L}^{-1}$ (this study) and 2) the groundwater flux out of the catchment calculated assuming a flow $q_{G W}$ of $9 \%$ of $q_{\text {stream }}$ (Sullivan et al., 2016a), and an average Li concentration [Li $]_{G W}$ of $0.78 \mu \mathrm{mol} \mathrm{L-1}$ (average Li concentration of well CZMW1; this study).

$$
X_{L i, \text { diss }}=q_{\text {stream }}[L i]_{\text {stream }}+q_{G W}[L i]_{G W}
$$

This approach provides estimates for total loss of $\mathrm{Li}, X_{L i}$, rock, of $992 \mathrm{~mol} \mathrm{~km}^{-2} \mathrm{yr}^{-1}$ and an aqueous flux, $X_{L i, a q}$, of $76 \mathrm{~mol} \mathrm{~km}^{-2} \mathrm{yr}^{-1}$, and reveals a particle flux $X_{L i, p a r t}$ of $916 \mathrm{~mol} \mathrm{~km}^{-2} \mathrm{yr}^{-1}$. According to this calculation, $92 \%$ of the $\mathrm{Li}$ is exported as particles and only $8 \%$ of the Li leaves the system as aqueous $\mathrm{Li}$. These results are similar to those from chemical weathering indices

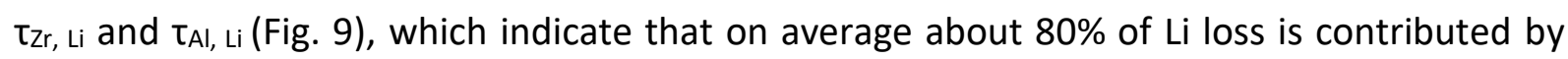
particle export in the soil zone. The small discrepancy between estimates could be due to the uncertainties of this model but is also consistent with loss of particles in the subsurface from deep rock (Kim et al., 2018) and by surface erosion.

These estimates of the relative proportion of aqueous and particle fluxes for $\mathrm{Li}$ at Shale Hills are also consistent with the estimated global average for Li transport in rivers, which is $80 \%$ as particle and 20\% aqueous load (Vigier and Godderis, 2015). However, most global models are based on the assumption that the loss of particles from soils occurs at the land surface as physical erosion: here, we argue that much of the particle loss occurs from within the soil profile and saprock. Our estimates are also consistent with the chemistry and mineralogy of regolith, soil and stream particles (Jin et al., 2010; Jin and Brantley, 2011; Kim et al., 2018) and B, Mg, and Fe isotope data (Noireaux et al., 2014; Yesavage et al., 2012; Ma et al, 2015; this study) showing that loss of most elements occurred predominantly as micronsized clay and oxide particles through macro-pores in the subsurface at Shale Hills.

\subsubsection{A missing flux in the Li isotope budget?}

Investigations of several isotopic systems in the SSHCZO including B, Mg and Fe (Ma et al., 2015; Yesavage et al., 2012; Noireaux et al., 2014; in press) all concluded that at least one reservoir has neither been sampled nor analyzed. For $\mathrm{B}, \mathrm{Mg}$, and $\mathrm{Fe}$, this missing reservoir was 
hypothesized to be particulates, i. e. clays that have been removed from the system in the subsurface over geological time. The conclusion is the same for the Li isotopic system.

The mass balance argument for a missing reservoir or flux can be summarized as follows. The only Li influx into the catchment is transformation of bedrock into soil: bedrock brings $\mathrm{Li}$ into the weathering zone with an average $\delta^{7} \mathrm{Li}$ rock value of near-zero $(-0.6 \%$ ). Aqueous and particulate export remove Li from the catchment, and both fluxes are characterized by higher $\delta^{7} \mathrm{Li}$ values than bedrock (average $\delta^{7} \mathrm{Li}_{\mathrm{aq}}=24.8 \%$ ond sampled stream sediments "Weir" and "SSL" with $\delta^{7} \mathrm{Li}$ values of $0.8 \%$ and $-0.3 \%$, respectively). The average $\delta^{7} \mathrm{Li}_{\text {aq }}$ value is calculated from the average $\mathrm{Li}$ concentrations and isotopic compositions of stream water (weighted averages considering discharge data from Xiao et al., 2019: $0.07 \mu \mathrm{mol} \mathrm{L}^{-1}$ and $30.2 \%$, respectively) and groundwater (arithmetic averages: $0.78 \mu \mathrm{mol} \mathrm{L}^{-1}$ and $19.1 \%$, respectively, for CZMW1) assuming that groundwater discharge is $9 \%$ of stream discharge (Sullivan et al., 2016a). We seek to determine what reservoir in the catchment is accumulating $\mathrm{Li}$ or what flux of $\mathrm{Li}$ is leaving the catchment with a negative $\delta^{7} \mathrm{Li}$ value to make the mass balance work.

To solve this, we revisit equation 7 and assume there is an unsampled flux, namely the subsurface particles, that removes Li from the catchment and completes the mass balance of Li. We calculate the isotopic composition of subsurface particles $\delta^{7} \mathrm{Li}_{\text {part, sub }}$ needed to close the mass balance and compare it to those measured for stream sediments. The fluxes $X_{L i, r o c k}, X_{L i, a q,}$ and $X_{L i, p a r t}$ are those calculated in section 5.3.1. The particulate flux $\left(X_{L i, p a r t}\right)$ consists of particles eroded from the surface by physical erosion ( $\left.X_{L i, p a r t, s u r f a c e}\right)$ and of particles eroded from the subsurface $\left(X_{L i, p a r t, s u b}\right)$. The partitioning of these two particulate fluxes can be roughly estimated from $\tau$ values of soil profiles (Fig. 9): surface soils show that on average about $60 \%$ of the total Li has been lost as particles in the subsurface whereas on average $20 \%$ of the total $\mathrm{Li}$ is retained, which is assumed to be removed by physical erosion. Here we assume that the flux from surface erosion $X_{L i, p a r t, \text { surface }}$ carries the isotopic composition of surface soils (average $\delta^{7} L_{\text {part,surface }}=0.8 \%$ ):

$$
X_{L i, p a r t, \text { sub }} \delta^{7} L i_{\text {part }, \text { sub }}=X_{L i, \text { rock }} \delta^{7} L i_{\text {rock }}-X_{L i, a q} \delta^{7} L i_{a q}-X_{L i, p a r t, \text { surface }} \delta^{7} L i_{\text {part,surface }}
$$


This approach reveals a calculated $\delta^{7} \mathrm{Li}$ value of the subsurface particulate flux as $-3.9 \%$, significantly lower than those measured for stream sediments and suspended sediment $(0.8 \%$ and $-0.3 \%$, respectively). This estimated value is relatively robust to uncertainties related to the large variations in $\delta^{7} \mathrm{Li}_{\text {aq }}$ observed for stream and groundwater because the aqueous flux accounts for less than $10 \%$ of the total Li flux (see 5.3.1.). To test this robustness, we calculated $\delta^{7} \mathrm{Li}$ values of the subsurface particulate flux by using minimum and maximum $\delta^{7} \mathrm{Li}_{\text {aq }}$ values of the stream outlet and groundwater (CZMW1), which reveals a range between $-4.1 \%$ and $3.6 \%$. We infer this signature could describe particles lost in the subsurface soil and saprock into groundwater - a flux that was not sampled. This value of $\delta^{7} \mathrm{Li}$ is well within the range of clays in soil and bedrock which range between $-5.7 \%$ and $-0.6 \%$ (Table 2 ). Therefore, we argue that it is possible that a flux of clay particles with isotopically low values of $\delta^{7} \mathrm{Li}$ are being lost now by subsurface erosion or were lost in the past from the catchment.

Subsurface particle transport might be enhanced at Shale Hills because of the clay-rich lithology, or because of periglacial conditions during the Last Glacial Maximum that left the upper 8 meters of the surface intensely fractured (Jin et al., 2010; Jin and Brantley, 2011; West et al., 2019). Previous researchers have argued that these particles may have removed from the catchment in the past (Ma et al., 2015; Noireaux et al., 2014; in press). Regardless of whether it occurred more in the past, frost cracking during the periglacial could have facilitated disaggregation of minerals in the shale that promoted preferential flushing of finegrained particles out of the system. Likewise, in the face of global warming, subsurface erosion of clays might become a prominent process in shale lithologies in Arctic regions when permafrost conditions retreats, which will influence the Li budget.

\subsection{Vegetation}

Vegetation generally does not play a major role in the global Li cycle and has a minimal effect on $\delta^{7} \mathrm{Li}_{\text {aq }}$ because vegetation has a low Li concentration and shows little isotopic fractionation compared to bedrock (Lemarchand et al., 2010; Clergue et al., 2015; Li et al., 2020). Consistent with this, a composite litter sample reflecting the mixed vegetation of the catchment reveals a $\delta^{7} \mathrm{Li}$ value of $-2.6 \%$ at the Shale Hills, which is close to average $\delta^{7} \mathrm{Li}_{\text {rock }}$ of $-0.6 \%$ ond almost identical to the average $\delta^{7} \mathrm{Li}_{\text {clay }}$ of $-3.0 \%$. However, this value is very distinct from the sampled water sources (ranging between 14.5 and 39.4\%o). Similar observations have been made in 
the granitic Strengbach catchment (France) where spruce vegetation shows a narrow range in $\delta^{7} \mathrm{Li}(-7.4$ and $-4.3 \%$ ) close to bedrock composition compared to the large range in ground-, stream, and soil water (-14.4 to $30.7 \%$ ) (Lemarchand et al., 2010). The fact that plants at Shale Hills show very similar isotopic compositions to clays and dissimilar compositions from lysimeter waters and groundwaters implies that plants might utilize a distinct water source whose isotopic composition is mainly controlled by clays as opposed to mobile water, whose isotopic signature is affected by precipitation of secondary minerals. This hypothesis might be in line with the concept of Brooks et al. (2010) who suggested that trees use tightly bound matrix water retained in small pores between clay mineral grains rather than mobile soil water and groundwater feeding the streams. Consistent with this, others have used detailed studies of $\mathrm{O}$ and $\mathrm{Sr}$ isotopes together with $\mathrm{Ca} / \mathrm{Sr}$ and Ge/Si ratios at Shale Hills (Gaines et al., 2016; Meek et al., 2016) to show that trees rely on shallow tightly-bound water as a water and nutrient source in depths less than $0.5 \mathrm{~m}$ rather than the mobile soil water sampled by suctioncup lysimeters. The Li isotopic compositions in soil clay and tree water (which are similar) are distinct from the bedrock and the deeper mobile waters in the soil, stream, and deeper aquifer.

\section{Conclusions}

Shale weathering exhibits distinct controls of the Li isotopic composition of water and residual solids. Positive Li isotopic signatures observed in stream, pore water and groundwater are governed by fractionation during sorption onto precipitated kaolinite and Fe-oxides. Vermiculitization also leads to variable but lower $\mathrm{Li}$ isotopic compositions in soil clays compared to parental material. The signature of bulk soils is affected by preferential removal of clay particles throughout the soil and within the weathered bedrock. The Li isotopic composition of vegetation is similar to those of soil clays and not like the waters in soil, stream, or groundwater. It is impossible to reconcile these reservoirs of $\mathrm{Li}$ (water and soil and biota) in terms of the protolith without invoking a missing reservoir, inferred to be Li-containing particles lost from depth.

Lithium isotopic fractionation observed in water is controlled by the availability of distinct adsorption sites on exchangeable interlayer sites of vermiculite (associated with no isotope fractionation) and on kaolinite/Fe-oxides (significant isotope fractionation). Simulations based 
on a box model suggest that only those deep groundwaters with $\delta^{7}$ Li values of $\sim 15 \%$ are explainable as steady state values whereas fluids with $\delta^{7} \mathrm{Li}$ values $>18 \%$, especially nearsurface waters, can only be explained as time-dependent, transient signals in an evolving system.

Soil clays are typically depleted in the heavy nuclide compared to parental material. In contrast, bulk soils can be enriched in the heavy nuclide because of the preferential loss of clay particles and accumulation of quartz.

Mass balance approaches reveal that Li depletion in shale is almost completely controlled by subsurface export of micron-sized Li-rich clay particles while the aqueous Li flux, which describes the dissolved Li flux, is very small. In fact, the present-day Li isotopic budget considering the sampled Li fluxes into the weathering zone and out of it suggests a missing reservoir which is attributed to such subsurface particle flux. It may be that this subsurface erosion was enhanced at Shale Hills in the past, when the catchment was periglacial and aquifers were recharged after the Last Glacial Maximum. Such subsurface particle losses are bound to be important in shale lithologies today, and especially for soils within periglacial climate regimes that are today experiencing warming. Loss of subsurface particles into groundwater must be included to balance the Li isotopic compositions of the different reservoirs in this system.

\section{Acknowledgements}

This work was financially supported by the National Science Foundation for the Susquehanna Shale Hills Critical Zone Observatory to SLB (EAR 13-31726). Additional funds for GS derived from the Penn State Institutes for Energy and the Environment. This research was conducted in Penn State's Stone Valley Forest, which is funded by the Penn State College of Agriculture Sciences, Department of Ecosystem Science and Management and managed by the staff of the Forestlands Management Office. Much thanks to members of the SSHCZO and the laboratory groups of SLB and MSF for laboratory and field help. GS thanks M. Dellinger for analytical advice. The manuscript benefited from constructive comments by the editor and three anonymous reviewers. 


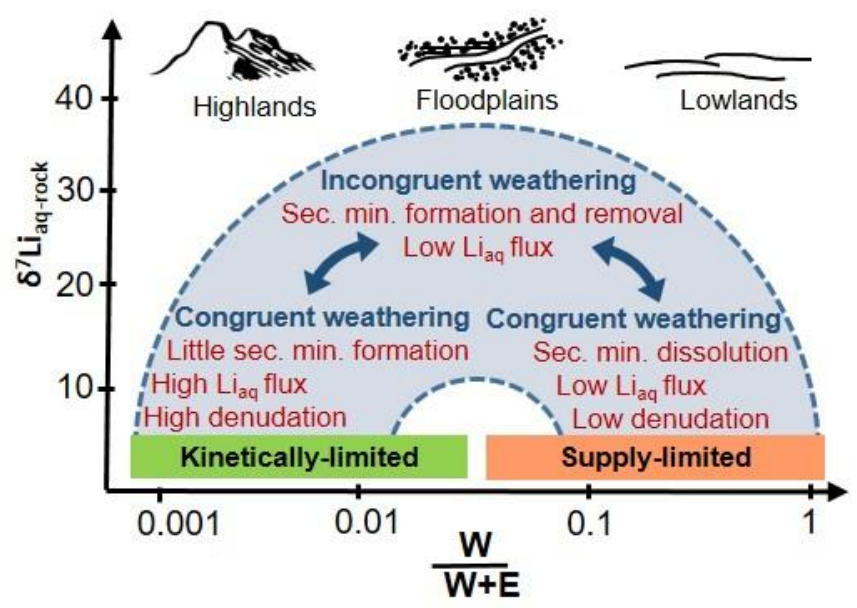

Fig. 1 Schematic illustration showing Li isotopic fractionation between rock and solute as a function of weathering intensity $(W /(W+E)$, where $W$ and $E$ refer to chemical weathering and physical erosion fluxes, respectively). This figure schematically summarizes the conclusions of several catchment studies after Dellinger et al. (2015). Highlands summarize mountain regions with high denudation (dominated by physical erosion) rates, which limits chemical weathering. Lowlands encompasses e.g. old shield terrains, which are characterized by very low erosion rates leading to a high weathering intensity (e.g., extent of chemical weathering). However the flux from chemical weathering is also low in these areas due to the low abundance of weatherable mineral phases. Floodplains show typically moderate weathering intensities and present areas with high amounts of fresh reactive mineral phases delivered from mountain areas. Shale Hills appears to plot at the top of the "boomerang" because it has a low aqueous Li flux but high values of $\delta^{7} \mathrm{Li}_{\text {aq }}$, as explained in the text. 


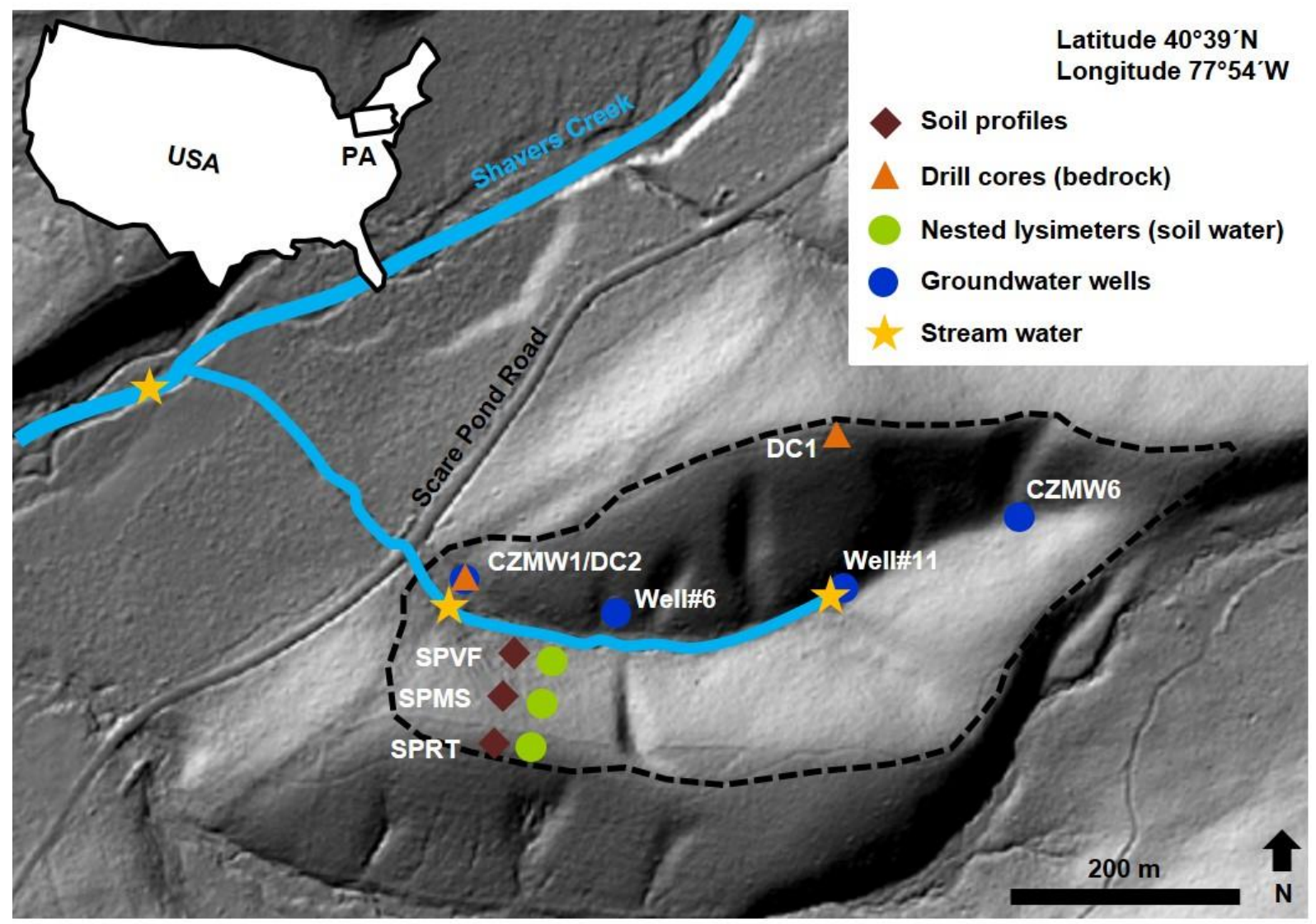

Fig. 2 The $0.08 \mathrm{~km}^{2}$ Shale Hill catchment part of the SSHCZO in Central Pennsylvania (PA) with a first-order ephemeral stream channel aligned from east to west in the valley (modified from West et al., 2013). This map shows the sample locations of soil profiles, bedrock, soil water, groundwater, and stream water. 
A) Li cycle at the first-order catchment Shale Hills

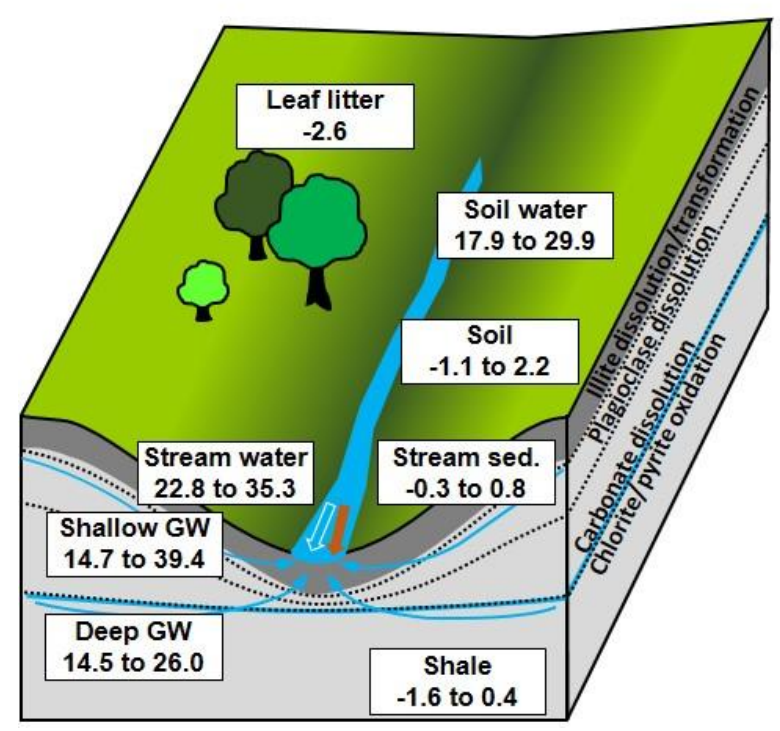

B) Global terrestrial Li cycle

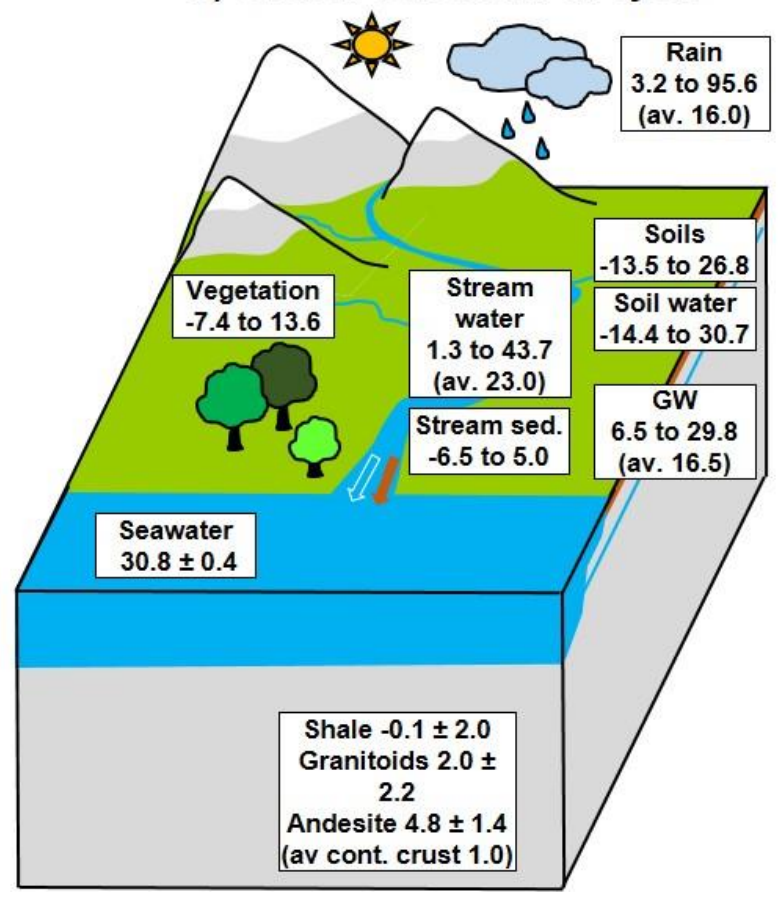

Fig. $3 \mathrm{~A}$ ) Overview of $\mathrm{Li}$ isotopic composition (provided values refer to $\delta^{7} \mathrm{Li}$ value in per mil) of the different reservoirs in Shale Hills, B) Global Li cycle showing the Li isotopic composition of the major reservoirs: average granitoid and andesite composition (literature compilation of Dellinger et al (2014)), average shale compiled data from Teng et al. (2004), Romer et al. (2014), Phan et al. (2016) and this study, estimated upper continental crust (Teng et al., 2004; Sauzeat et al., 2015), suspended stream sediments (Huh et al., 2001; Millot et al., 2010b, Dellinger et al., 2015, 2017; Liu et al., 2015; Pogge von Strandmann et al., 2017b; Weynell et al., 2017), vegetation (Lemarchand et al., 2010; Clergue et al., 2015; Li et al., 2020), stream water (see compilation of Hindshaw et al., (2018)), seawater (compiled data by Rosner et al., (2007)), rain water (Pistiner and Henderson, 2003; Millot et al., 2010a), groundwater (Negrel et al., 2012; Bagard et al., 2015; Liu et al., 2015; Wanner et al., 2017; this study), and soils (Huh et al., 2004; Kisakürek et al., 2004; Rudnick et al., 2004; Lemarchand et al., 2010; Pogge von Strandmann et al., 2012; Ryu et al., 2014; Clergue et al., 2015; Hindshaw et al., 2019b, this study). 


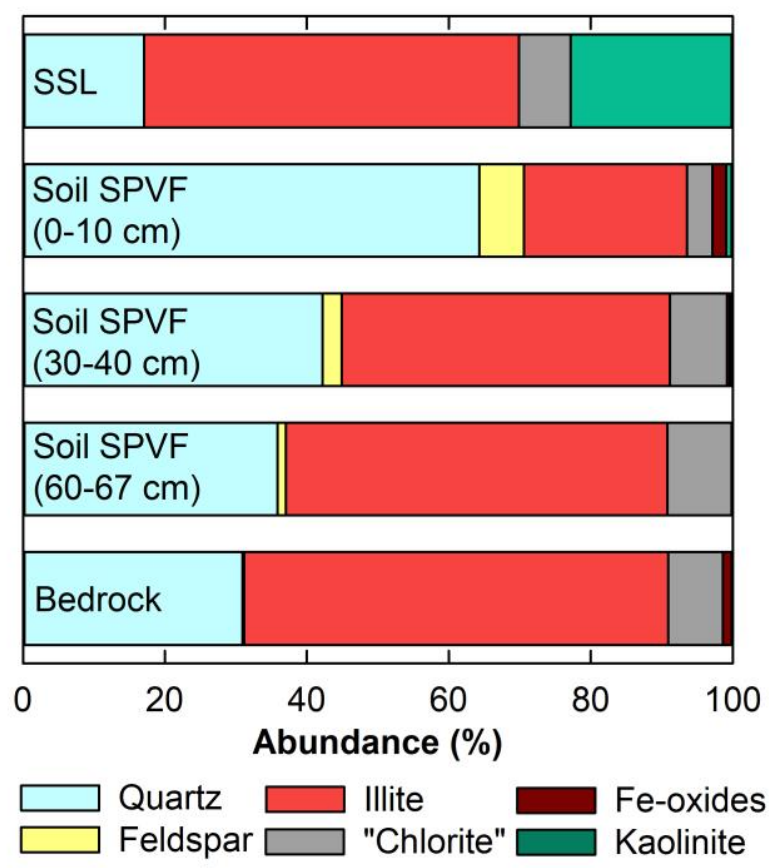

Fig. 4 Mineral composition of the bedrock, soil and suspended stream sediment. Data for the soil profile at valley floor site SPVF and bedrock are published in Jin et al. (2010); mineral composition for suspended stream sediment "SSL" is from this study. "Chlorite" includes chlorite, vermiculite and HIV. 
Chlorite

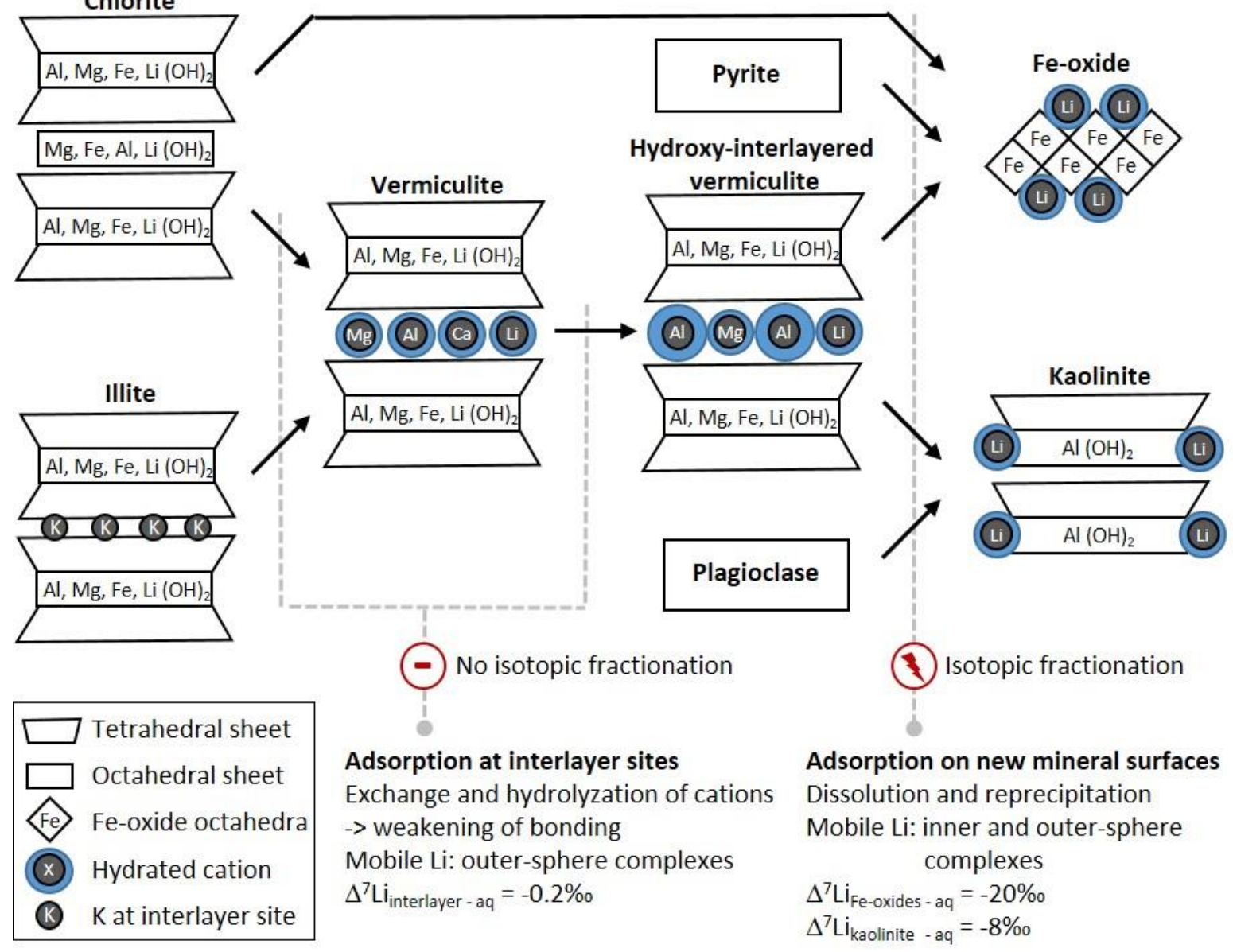

Fig. 5 Schematic illustration of clay transformation and secondary mineral precipitation processes in SSHCZO, which affect Li isotopic fractionation. Isotopic fractionation factors are from Hindshaw et al. (2019a), Li and Liu (2020) and Wimpenny et al. (2010). 

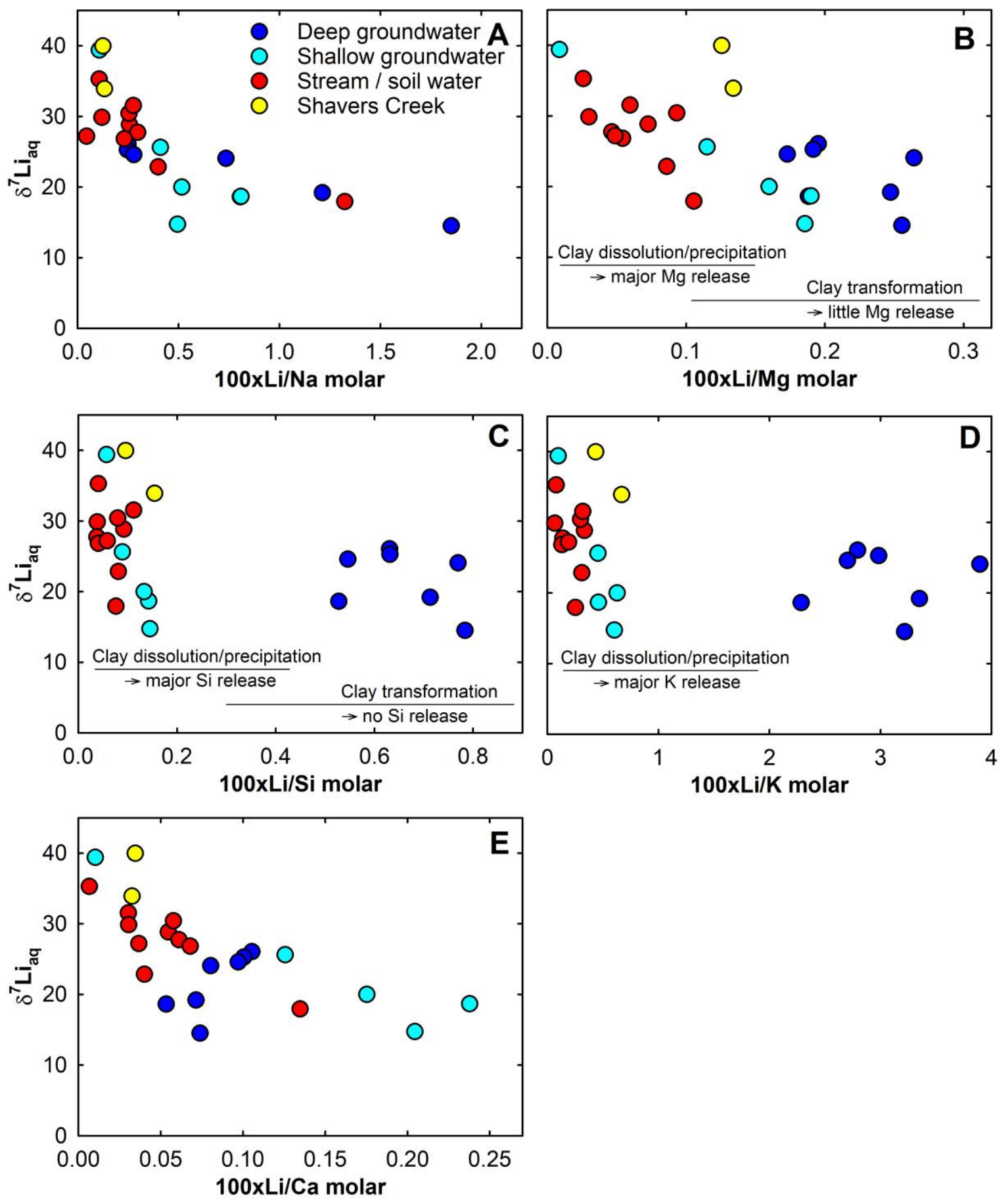

Fig. 6 Lithium isotopic composition of water samples versus Li/element ratio (mol:mol). 


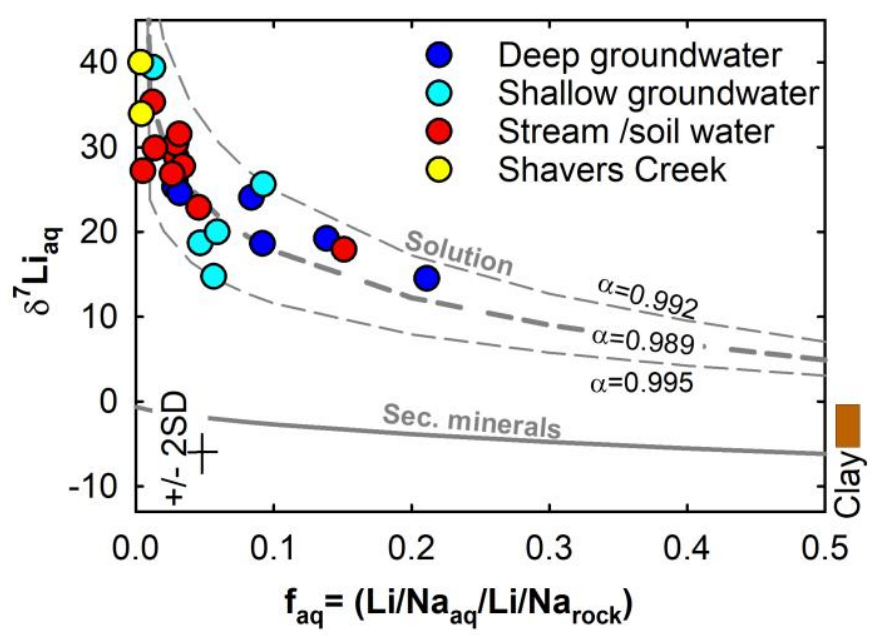

Fig. 7 Lithium isotopic composition of water samples versus the Li fraction remaining in solution $\mathrm{f}_{\text {aqq }}$. The grey curves describe a Rayleigh distillation model for $\delta^{7} \mathrm{Li}_{\text {aq }}$ of near-surface water (shallow groundwater and stream/soil water) showing the theoretical evolution of the isotopic composition of the solution (dashed line) and of secondary minerals (solid line). All data plot between curves with an isotopic fractionation factor $\Delta^{7} \mathrm{Li}_{\text {sec-aq }}$ of $-5 \%$ o $(\alpha=0.995)$ and $-11 \%$ o ( $\alpha=0.989)$, respectively with the best for $\Delta^{7} L_{\text {sec-aq }}$ of $-8 \%$ o $(\alpha=0.992)$. 
a

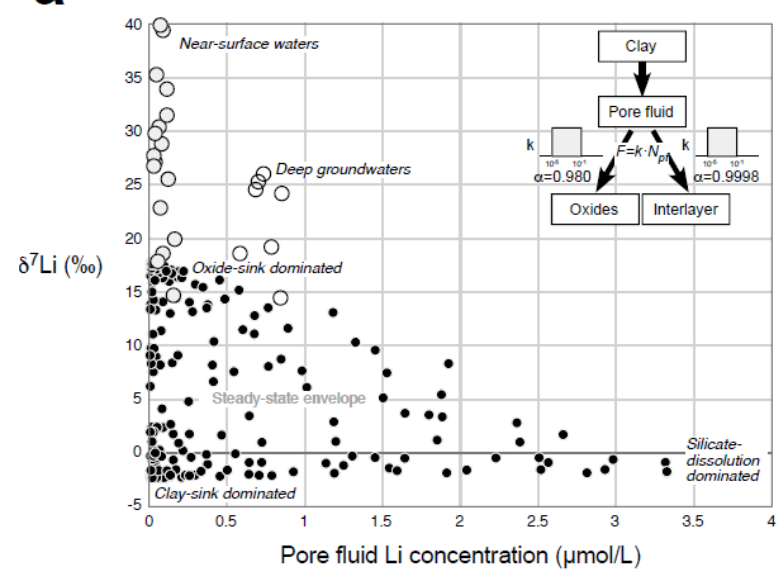

C

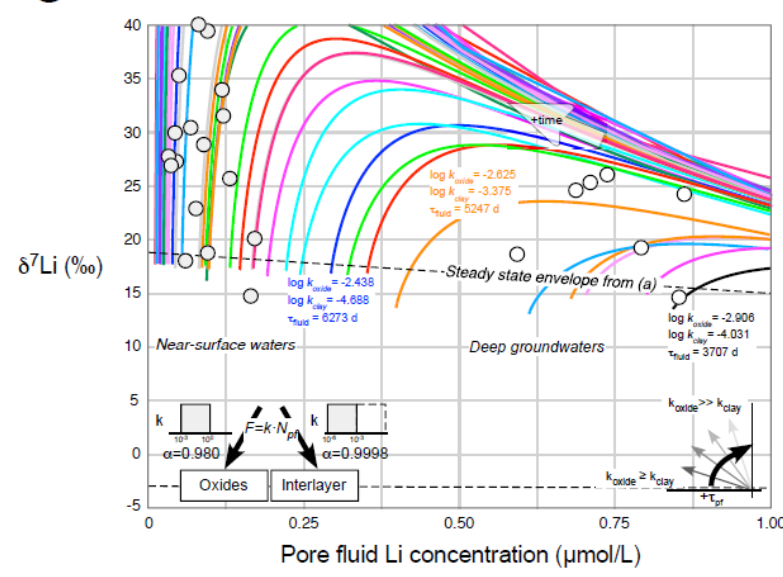

b

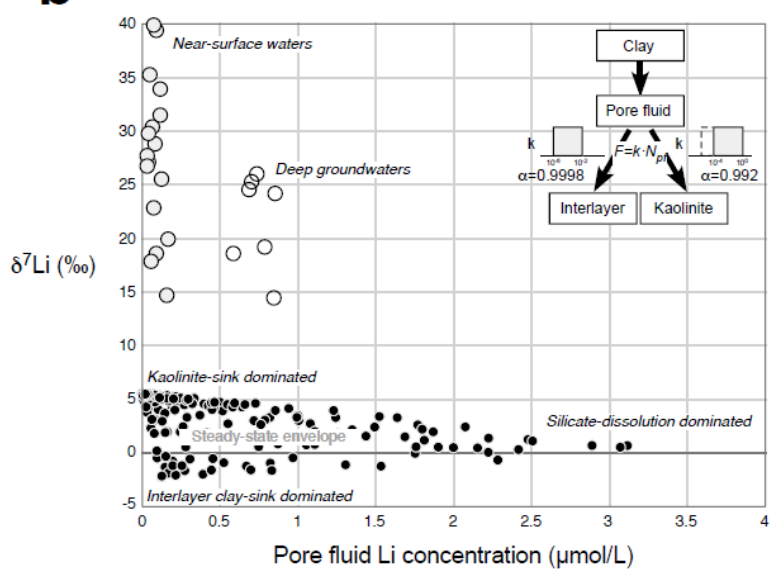

d

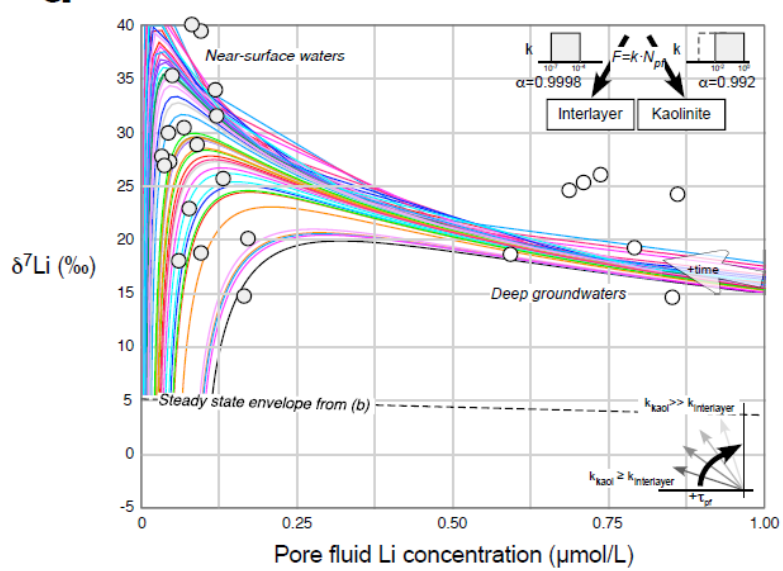

Fig. 8 Model-derived soil pore fluid Li isotopic composition ( $\delta^{7} \mathrm{Li}, \%$ ) and Li concentration $(\mu \mathrm{mol} / \mathrm{L})$ at either $(\mathrm{a}-\mathrm{b})$ steady state or $(\mathrm{c}-\mathrm{d})$ transient states $(\bullet)$, with measured data indicated by the open (near-surface water) and gray (deep groundwater) symbols. The model framework used to generate the output in (a) and (c) is shown in the schematic in panel (a); the framework used in (b) and (d) is shown in panel (b). In all schematics, $F$ is the mass flux in $\mu \mathrm{mol} / \mathrm{d}$ and $N_{p f}$ is the mass of $\mathrm{Li}(\mu \mathrm{mol})$ in the pore fluid reservoir. We assume a range of firstorder rate constants $(k)$ associated with Li removal by the interlayers of clay ( $\alpha=0.9998)$, Feoxide precipitation ( $\alpha=0.980)$, and/or kaolinite precipitation ( $\alpha=0.992)$. In each scenario, the residence time of pore fluid due to advection ( $\tau_{\mathrm{pf}}=5-20$ years) and the rate constants associated with Li removal in oxides and/or clays (as indicated in all panels) is varied using a Sobol Sequence sampling routine. The $\delta^{7} \mathrm{Li}$ of the silicate dissolution flux is assumed to be $2.5 \%$, and the dissolution rate is assumed to be $3.2 \cdot 10^{-7} \mu \mathrm{mol} \mathrm{Li} / \mathrm{d}$ (based on a mineral dissolution rate of $\sim 4.75 \cdot 10^{-12} \mathrm{~mol} / \mathrm{m}^{2} / \mathrm{d}$, a specific surface area of $26 \mathrm{~m}^{2} / \mathrm{g}$, a porosity of 0.4 , a mineral molar mass of $403.3 \mathrm{~g} / \mathrm{mol}$, a Li concentration of $18 \mu \mathrm{mol} / \mathrm{g}$ (Jin et al., 2010), a 
fraction of mineral in rock of 0.2 , and a mineral density of $\left.3 \mathrm{~g} / \mathrm{cm}^{3}\right)$. In panels (c) and (d), the $\mathrm{Li}$ concentration of the advecting fluid is $2 \mu \mathrm{mol} / \mathrm{L}$. 


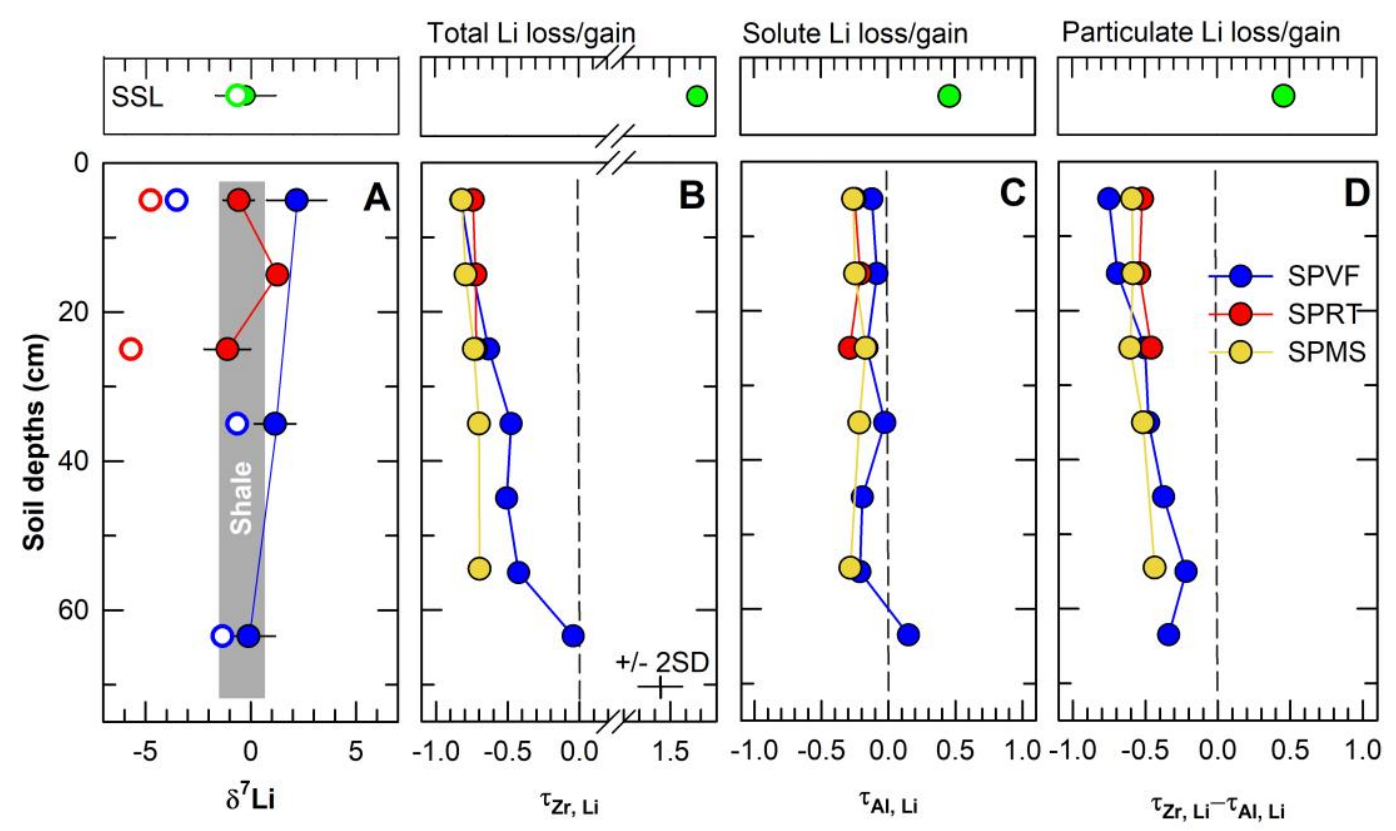

Fig. 9 Lithium isotopic composition and mass transfer coefficient $\tau$ for the soil profiles SPVF, SPMS and SPRT and suspended stream sediment (SSL): A) $\delta^{7}$ Li values for bulk samples $(<2 \mathrm{~mm})$ (filled circles) and calculated $\delta^{7} \mathrm{Li}_{\text {clay }}$ values (open circles). B) $\tau_{\mathrm{Zr}, \mathrm{Li}}$ values indicating total loss (negative values) or gain (positive) of Li. Soils show a total Li loss up to $80 \%$ whereas $\mathrm{Li}$ is significantly enriched in the suspended sediment load "SSL". C) $\tau_{\mathrm{Al}, \mathrm{Li}}$ values to quantify Li loss or gain by solute following Hasenmueller et al. (2017). D) $\tau_{\mathrm{Zr}, \mathrm{Li}}-\tau_{\mathrm{Al}, \mathrm{Li}}$ is a measurement for particulate Li loss or gain. Soils are depleted in Li ranging between 20 and $75 \%$ by particulate export. Sample "SSL" is enriched by particulate Li. The soil profiles do not return to bedrock values at the bottom, indicating that particulate export continues into the weathered bedrock, as shown by Kim et al. (2018). 

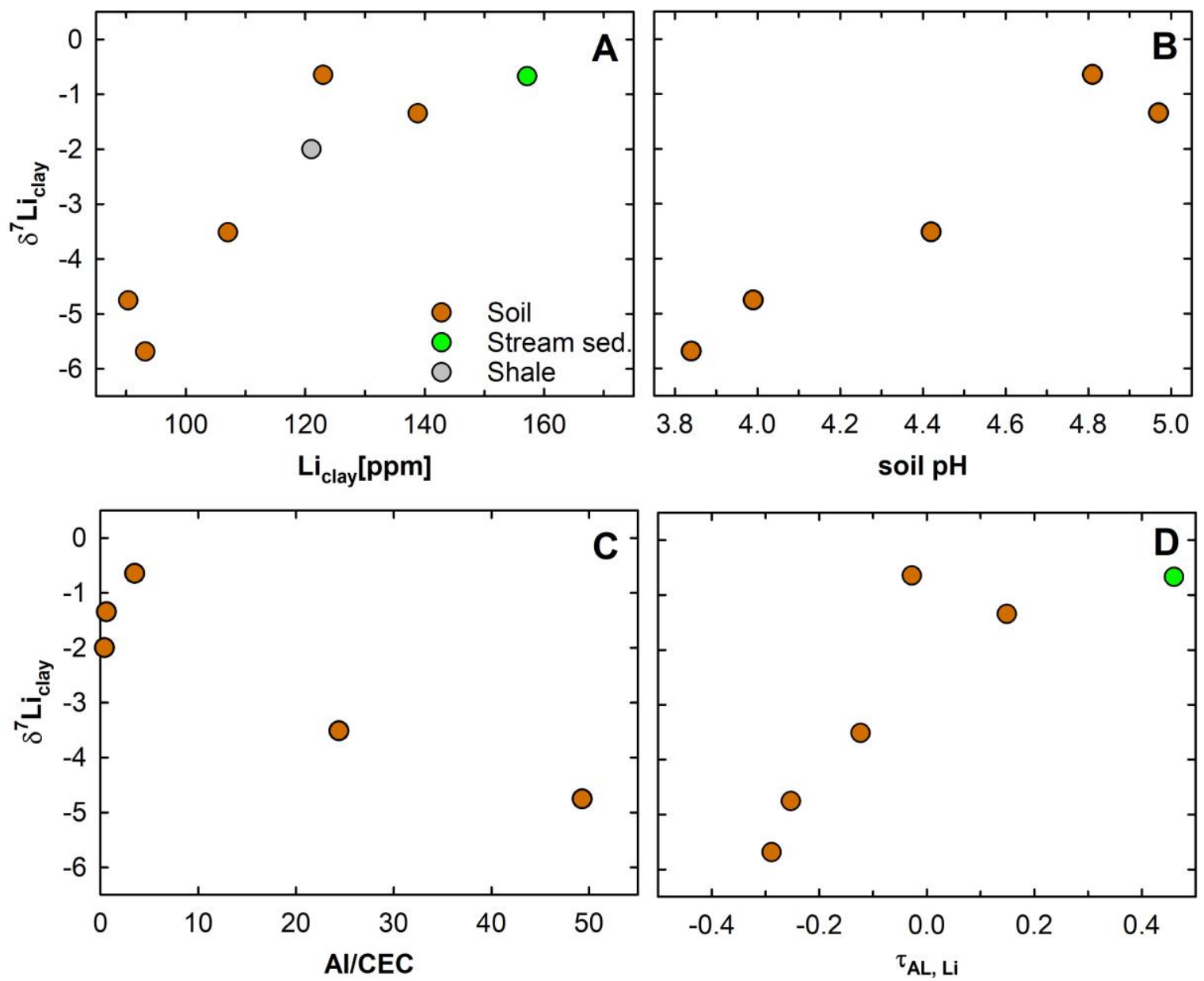

Fig. 10 Calculated $\delta^{7} \mathrm{Li}_{\text {clay }}$ values of soil, stream sediment and bedrock samples versus A) calculated Li concentration of the clay fraction, B) soil pH (only for soil samples), C) cation exchange capacity (CEC) for $\mathrm{Al}$, and $\mathrm{D}) \tau_{\mathrm{Al}, \mathrm{Li}}$ values as indice for Li loss/gain as solute. 


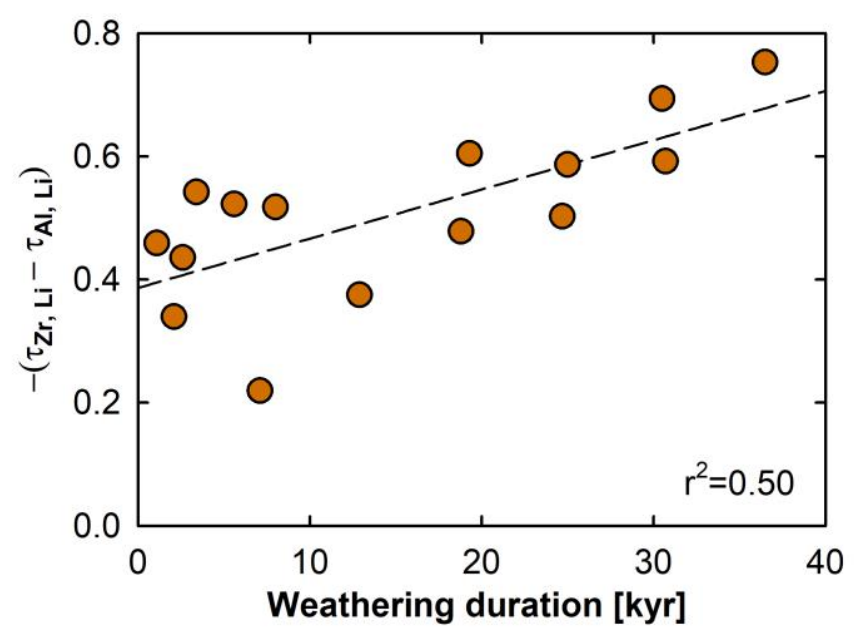

Fig. 11 Fractional depletion of Li from soils by the process of subsurface particulate transport $-\left(\tau_{Z r, L i}-\tau_{A l, L i}\right)$ plotted versus weathering duration. Lithium depletion in soils by particle export correlates with weathering duration obtained by U-series (Ma et al., 2013). This plot indicates that about $40 \%$ of Li has been already lost by particles at zero duration of weathering, i.e., particulates are lost in the subsurface below the soil zone. 


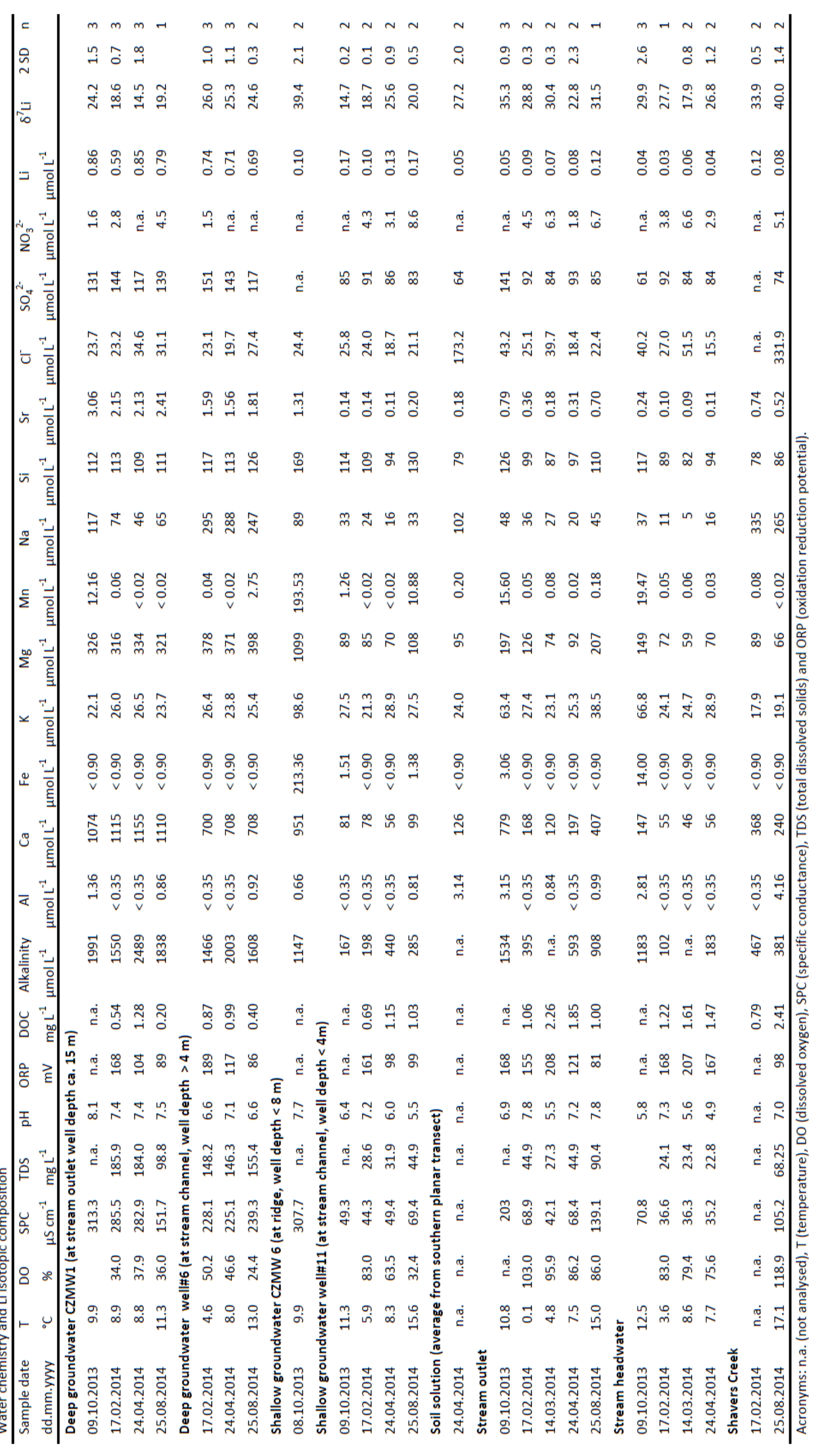


Table 2

Lithium isotopic composition and Li concentration of bedrock, soils, stream sediments and vegetation, and mass transfer coefficients $\tau$ for soil samples.

\begin{tabular}{|c|c|c|c|c|c|c|c|c|c|}
\hline Sample name & $\begin{array}{c}\text { Depth range } \\
(\mathrm{m})\end{array}$ & $\delta^{7} \mathrm{Li}$ & $2 S D$ & $\mathrm{n}$ & $\begin{array}{c}\mathrm{Li} \\
(\mathrm{ppm})\end{array}$ & ${ }^{*} \delta^{7} \mathrm{Li}_{\text {clay }}$ & $\begin{array}{l}{ }^{*} \mathrm{Li}_{\text {clay }} \\
(\mathrm{ppm})\end{array}$ & $\tau_{\mathrm{Zr}, \mathrm{Li}}$ & $\tau_{\mathrm{Al}, \mathrm{Li}}$ \\
\hline \multicolumn{10}{|l|}{ Shale } \\
\hline DC1-36 & $19.90-20.10$ & -1.6 & 0.3 & 4 & 86 & & & & \\
\hline DC2 51-52 & $15.50-15.80$ & -0.8 & 0.7 & 2 & 85 & av. -2.0 & av. 121 & & \\
\hline DC1-38 & $24.40-24.60$ & 0.4 & 1.8 & 3 & 79 & & & & \\
\hline DC1-8 & $1.10-1.20$ & - & & & 103 & & & & \\
\hline DC2-1718 & $5.20-5.50$ & - & & & 80 & & & & \\
\hline DC2-2223 & $6.70-7.00$ & - & & & 84 & & & & \\
\hline \multicolumn{10}{|c|}{ Soils from the southern planar transect } \\
\hline \multicolumn{10}{|l|}{ Ridgetop } \\
\hline SPRT0010 & $0-0.10$ & -0.6 & 0.7 & 5 & 44 & -4.8 & 90 & -0.73 & -0.20 \\
\hline SPRT 1020 & $0.10-0.20$ & 1.3 & 0.0 & 2 & 47 & & & -0.71 & -0.17 \\
\hline SPRT 2030 & $0.20-0.30$ & -1.1 & 1.1 & 4 & 43 & -5.7 & 93 & -0.70 & -0.24 \\
\hline \multicolumn{10}{|l|}{ Midslope } \\
\hline SPMS 0010 & $0-0.10$ & - & & & 39 & & 93 & -0.81 & -0.22 \\
\hline SPMS 1020 & $0.10-0.20$ & - & & & 43 & & & -0.78 & -0.19 \\
\hline SPMS 2030 & $0.20-0.30$ & - & & & 49 & & 127 & -0.72 & -0.11 \\
\hline SPMS 4050 & $0.40-0.50$ & - & & & 52 & & & -0.68 & \\
\hline SPMS 5059 & $0.50-0.59$ & - & & & 50 & & 105 & -0.68 & -0.16 \\
\hline \multicolumn{10}{|l|}{ Valley floor } \\
\hline SPVF0010 & $0-0.10$ & 2.2 & 1.4 & 4 & 38 & -3.5 & 107 & -0.81 & -0.06 \\
\hline SPVF1020 & $0.10-0.20$ & - & & & 51 & & & -0.73 & -0.03 \\
\hline SPVF2030 & $0.20-0.30$ & - & & & 59 & & & -0.61 & -0.11 \\
\hline SPVF 3040 & $0.30-0.40$ & 1.2 & 1.0 & 2 & 72 & -0.6 & 123 & -0.44 & 0.04 \\
\hline SPVF4050 & $0.40-0.50$ & - & & & 64 & & & -0.41 & -0.04 \\
\hline SPVF5060 & $0.50-0.60$ & - & & & 66 & & & -0.40 & -0.18 \\
\hline SPVF6067 & $0.60-0.67$ & -0.1 & 1.3 & 4 & 91 & -1.3 & 139 & -0.19 & 0.15 \\
\hline \multicolumn{10}{|l|}{ Stream sediments } \\
\hline SSL 26 May 2014 & & -0.3 & 1.4 & 4 & 132 & -0.7 & 157 & 1.25 & 0.55 \\
\hline Weir Sed. 2013 & & 0.8 & 1.4 & 4 & 78 & & & -0.22 & \\
\hline \multicolumn{10}{|l|}{ Plant sample } \\
\hline Leaf litter & & -2.6 & 0.8 & & $50 \mathrm{ppb}$ & & & & \\
\hline
\end{tabular}

*) Calculated Li isotopic compositions and Li concentrations for the fraction of secondary minerals calculated by a mass balance approach using the data of this study and the mineral composition published by Jin et al. (2010). 


\section{References}

Anderson S. P., Dietrich W. E. and Brimhall G. H. (2002) Weathering profiles, mass-balance analysis, and rates of solute loss: Linkages between weathering and erosion in a small, steep catchment. Bull. Geol. Soc. Am. 114, 1143-1158.

Andrews D. M., Lin H., Zhu Q., Jin L., Brantley S. L. (2011) Hot Spots and Hot Moments of Dissolved Organic Carbon Export and Soil Organic Carbon Storage in the Shale Hills Catchment. Vadose Zone J. 10, 943-954.

Bagard M.-L., Schmitt A.-D., Chabaux F., Pokrovsky O. S., Viers J., Stille P., Labolle F. and Prokushkin A. S. (2013) Biogeochemistry of stable $\mathrm{Ca}$ and radiogenic $\mathrm{Sr}$ isotopes in a larch-covered permafrost-dominated watershed of Central Siberia. Geochim. Cosmochim. Acta 114, 169187.

Bagard M.-L., West A. J., Newman K. and Basu, A. R. (2015) Lithium isotope fractionation in the Ganges-Brahmaputra floodplain and implications for groundwater impact on seawater isotopic composition. Earth Planet. Sci. Lett. 432, 404-414.

Bastian L., Revel M., Bayon G., Dufour A. and Vigier N. (2017) Abrupt response of chemical weathering to Late Quaternary hydroclimate changes in northeast Africa. Sci. Rep. 7, 44231.

Bern C.R. and Yesavage T. (2018) Dual-phase mass balance modeling of small mineral particle losses from sedimentary rock-derived soils. Chem. Geol. 476, 441-455.

Bern C.R. and Yesavage T. (2019) Comment on "Particle fluxes in groundwater change subsurface shale rock chemistry over geologic time". Earth Planet. Sci. Lett. 514, 166-168.

Berner R. A., Lasaga A. C. and Garrels, R. M. (1983) The carbonate-silicate geochemical cycle and its effect in the atmospheric carbondioxide over the past 100 million year. Am. J. Sci. 283, 641683.

Bouchez J., von Blanckenburg F. and Schuessler J.A. (2013) Modeling novel stable isotope ratios in the weathering zone. Am. J. Sci. 313, 267-308.

Brantley S. L., Holleran M.E., Jin L. and Bazilevskaya E. (2013) Probing deep weathering in the Shale Hills Critical Zone Observatory, Pennsylvania (USA): The hypothesis of nested chemical reaction fronts in the subsurface. Earth Surf. Process. Landf. 38, 1280-1298.

Brantley S. L., White T., West N., Williams J. Z., Forsythe B., Shapich D., Kaye J., Lin H., Shi Y., Kaye M., Herndon E., Davis K. J., He Y., Eissenstat D., Weitzman J., DiBase R., Li L., Reed W., Brubaker K. and Gu X. (2018) Susquehanna Shale Hills Critical Zone Observatory: Shale Hills in the Context of Shaver's Creek Watershed. Vadose Zone J. 17, 1-19.

Brimhall G. H. and Dietrich W. E. (1987) Constitutive mass balance relations between chemical composition, volume, density, porosity, and strain in metasomatic hydrochemical systems results on weathering and pedogenesis. Geochim. Cosmochim. Acta 51, 567-587.

Brooks J.R., Barnard H.R., Coulombe R., McDonnell, J.J. (2010) Ecohydrologic separation of water between trees and streams in a Mediterranean climate. Nat. Geosci. 3, 100-104.

Chadwick O. A., Brimhall G. H. and Hendricks D. M. (1990) From a black to a gray box - a mass balance interpretation of pedogenesis. Geomorphology 3, 369-390.

Chan L. H. and Hein J. R. (2007) Lithium contents and isotopic compositions of ferromanganese deposits from the global ocean. Deep-Sea PT II 54, 1147-1162.

Chanda P. and Fantle M. S. (2017) Quantifying the effect of diagenetic recrystallization on the Mg isotopic composition of marine carbonates. Geochim. Cosmochim. Acta 204, 219-239.

Clergue C., Dellinge, M., Buss H. L., Gaillardet J., Benedetti M. F. and Dessert C. (2015) Influence of atmospheric deposits and secondary minerals on $\mathrm{Li}$ isotopes budget in a highly weathered catchment, Guadeloupe (Lesser Antilles). Chem. Geol. 414, 28-41.

Dellinger M., Gaillardet J., Bouchez J., Calmels D., Galy V., Hilton .G., Louvat P. and France-Lanord C. (2014) Lithium isotopes in large rivers reveal the cannibalistic nature of modern continental weathering and erosion. Earth Planet. Sci. Lett. 401, 359-372. 
Dellinger M., Gaillardet J., Bouchez J., Calmels D., Louvat P., Dosseto A., Gorge C., Alanoca L. and Maurice, L. (2015) Riverine Li isotope fractionation in the Amazon River basin controlled by the weathering regimes. Geochim. Cosmochim. Acta 164, 71-93.

Dellinger M., Bouchez J., Gaillardet J., Faure L. and Moureau J. (2017) Tracing weathering regimes using the lithium isotope composition of detrital sediments. Geology 45, 411-414.

Dellinger M., West A. J., Paris G., Adkins J. F., Pogge von Strandmann, P. A. E., Ullmann C. V., Eagle R. A., Freitas P., Bagard M.-L., Ries J. B., Corsetti F. A., Perez-Huerta A. and Kampf A. R. (2018) The $\mathrm{Li}$ isotope composition of marine biogenic carbonates: Patterns and mechanisms. Geochim. Cosmochim. Acta 236, 315-335.

Dosseto A., Vigier N., Joannes-Boyau R., Moffat I., Singh T. and Srivastava P. (2015) Rapid response of silicate weathering rates to climate change in the Himalaya. Geochem. Perspect. Lett. 1, 1018.

Dupuis R., Benoit M., Tuckerman M. E. and Meheut M. (2017) Importance of a fully anharmonic treatment of equilibrium isotope fractionation properties of dissolved ionic Species as evidenced by Li+(aq). Acc. Chem. Res. 50, 1597-1605.

Fairén A. G., Losa-Adams E., Gil-Lozano C., Gago-Duport L., Uceda E. R., Squyres S. W., Rodriguez J. A. P., Davila A. F. and McKay C. P. (2015) Tracking the weathering of basalts on Mars using lithium isotope fractionation models. Geochem. Geophys. Geosyst. 16, 1172-1197.

Gaillardet J., Dupre B., Louvat P. and Allegre CJ. (1999) Global silicate weathering and $\mathrm{CO}_{2}$ consumption rates deduced from the chemistry of large rivers. Chem. Geol. 159, 3-30.

Gaines K. P., Stanley J. W., Meinzer F. C., McCulloh K. A., Woodruff D. R., Chen W., Adams T. S., Lin H. and Eissenstat D. M. (2016) Reliance on shallow soil water in a mixed-hardwood forest in central Pennsylvania. Tree Physiol. 36, 444-458.

Giesler R., Ilvesniemi H., Nyberg L., van Hees P., Starr M., Bishop K., Kareinen T. and Lundstrom U.S. (2000) Distribution and mobilization of Al, Fe and $\mathrm{Si}$ in three podzolic soil profiles in relation to the humus layer. Geoderma 94, 249-263.

Gislason S.R., Arnorsson S., Armannsson H. (1996) Chemical weathering of basalt in southwest Iceland: effects of runoff, age or rocks and vegetative/glacial cover. Am. J. Sci. 296, 837-907.

Gu X., Rempe D. M., Dietrich W. E., West A. J., Lin T.-C., Jin L. and Brantley, S. L. (2020) Chemical reactions, porosity, and microfracturing in shale during weathering: The effect of erosion rate. Geochim. Cosmochim. Acta 269, 63-100.

Hall J. M., Chan L. H., McDonough W.F. and Turekian K. K. (2005) Determination of the lithium isotopic composition of planktic foraminifera and its application as a paleo-seawater proxy. Mar. Geol. 217, 255-265.

Hartmann J. and Moosdorf N. (2012) The new global lithological map database GLiM: A representation of rock properties at the Earth surface. Geochem. Geophys. Geosyst. 13, Q12004.

Hasenmueller E. A., Gu X., Weitzman J. N., Adams T. S., Stinchcomb G. E., Eissenstat D. M., Drohan P. J., Brantley S. L. and Kaye J. P. (2017) Weathering of rock to regolith: The activity of deep roots in bedrock fractures. Geoderma 300, 11-31.

Hathorne E.C. and James R. H. (2006) Temporal record of lithium in seawater: A tracer for silicate weathering. Earth Planet. Sci. Lett. 246, 393-406.

Henchiri S., Gaillardet J., Dellinger M., Bouchez J. and Spencer R. G. M. (2016) Riverine dissolved lithium isotopic signatures in low-relief central Africa and their link to weathering regimes. Geophys. Res. Lett. 43, 4391-4399.

Herndon E. M. and Brantley S. L. (2011) Movement of manganese contamination through the Critical Zone. Appl. Geochemistry 26, S40-S43.

Herndon E. M., Jin L. X., Andrews D. M., Eissenstat D. M. and Brantley S. L. (2015) Importance of vegetation for manganese cycling in temperate forested watersheds. Global Biogeochem. Cy. 29, 160-174. 
Herndon E. M., Steinhoefel G., Dere A. L. D. and Sullivan P.L. (2018) Perennial flow through convergent hillslopes explains chemodynamic solute behavior in a shale headwater catchment. Chem. Geol. 493, 413-425.

Hindshaw R. S., Aciego S. M. and Tipper E. T. (2018) Li and U Isotopes as a Potential Tool for Monitoring Active Layer Deepening in Permafrost Dominated Catchments. Front. Earth Sci. 6, 102.

Hindshaw R. S., Tosca R., Gout T. L., Farnan I., Tosca N. J. and Tipper E. T. (2019a) Experimental constraints on Li isotope fractionation during clay formation. Geochim. Cosmochim. Acta 250, 219-237.

Hindshaw R. S., Teisserenc R., Le Dantec T. and Tananaev N. (2019b) Seasonal change of geochemical sources and processes in the Yenisei River: A Sr, Mg and Li isotope study. Geochim. Cosmochim. Acta 255, 222-236.

Holland H. D. (1978) The chemistry of the atmosphere and ocean. Wiley, New York.

Huh Y., Chan L. H., Zhang L. and Edmond J. M. (1998) Lithium and its isotopes in major world rivers: Implications for weathering and the oceanic budget. Geochim. Cosmochim. Acta 62, 20392051.

Huh Y., Chan L. H. and Edmond J. M. (2001) Lithium isotopes as a probe of weathering processes: Orinoco River. Earth Planet. Sci. Lett. 194, 189-199.

Huh Y., Chan L. H. and Chadwick O. A. (2004) Behavior of lithium and its isotopes during weathering of Hawaiian basalt. Geochem. Geophys. Geosyst. 5, Q09002.

Jin L., Ravella R., Ketchum B., Bierman P. R., Heaney P., White T. S. and Brantley S. L. (2010) Mineral weathering and elemental transport during hillslope evolution at the Susquehanna/Shale Hills Critical Zone Observatory. Geochim. Cosmochim. Acta 74, 3669-3691.

Jin L. and Brantley S. L. (2011) Soil chemistry and shale weathering on a hillslope influenced by convergent hydrologic flow regime at the Susquehanna/Shale Hills Critical Zone Observatory. Appl. Geochemistry 26, S51-S56.

Jin L., Andrews D. M., Holmes G. H., Lin H. and Brantley S. L. (2011) Opening the "Black Box": Water Chemistry Reveals Hydrological Controls on Weathering in the Susquehanna Shale Hills Critical Zone Observatory. Vadose Zone J. 10, 928.

Jochum K.-P., Nohl L., Herwig K., Lammel E., Stoll B. and Hofmann A. W. (2005) GeoReM: A new geochemical database for reference materials and isotopic standards. Geostand. Geoanal. Res. 29, 333-338.

Kim H., Gu X. and Brantley S. L. (2018) Particle fluxes in groundwater change subsurface shale rock chemistry over geologic time. Earth Planet. Sci. Lett. 500, 180-191.

Kim H., Gu X. and Brantley S. L. (2019) Reply to the comment on "Particle fluxes in groundwater change subsurface shale rock chemistry over geologic time". Earth Planet. Sci. Lett. 514, 169171.

Kisakürek B., Widdowson M. and James R. H. (2004) Behaviour of Li isotopes during continental weathering: the Bidar laterite profile, India. Chem. Geol. 212, 27-44.

Kisakürek B., James R.H. and Harris N. B. W. (2005) Li and delta Li-7 in Himalayan rivers: Proxies for silicate weathering? Earth Planet. Sci. Lett. 237, 387-401.

Kump L. R., Brantley S. L. and Athur M. A. (2000) Chemical weathering, atmospheric $\mathrm{CO}_{2}$, and climate. Annu. Rev. Earth Planet. Sci. 28, 611-667.

Kuntz B.W., Rubin S., Berkowitz B. and Singha K. (2011) Quantifying Solute Transport at the Shale Hills Criticial Zone Observatory. Vadose Zone J. 10, 843.

Lechler M., Pogge von Strandmann P. A. E., Jenkyns H. C., Prosser G. and Parente, M. (2015) Lithiumisotope evidence for enhanced silicate weathering during OAE 1a (Early Aptian Selli event). Earth Planet. Sci. Lett. 432, 210-222.

Lemarchand E., Chabaux F., Vigier N., Millot R. and Pierret M.-C. (2010) Lithium isotope systematics in a forested granitic catchment (Strengbach, Vosges Mountains, France). Geochim.

Cosmochim. Acta 74, 4612-4628. 
Li G. and West A. J. (2014) Evolution of Cenozoic seawater lithium isotopes: Coupling of global denudation regime and shifting seawater sinks. Earth Planet. Sci. Lett. 401, 284-293.

Li W. and Liu X.-M. (2020) Experimental investigation of lithium isotope fractionation during kaolinite adsorption: Implications for chemical weathering, Cosmochim. Acta 284, 156-172.

Li W., Liu X.-M. and Chadwick O.A. (2020) Lithium isotope behavior in Hawaiian regoliths: Soil-atmosphere-biosphere exchanges Geochim. Cosmochim. Acta 285, 175-192.

Lin H. S., Kogelmann W., Walker C. and Bruns M. A. (2006) Soil moisture patterns in a forested catchment: A hydropedological perspective. Geoderma 131, 345-368.

Liu X. M., Wanner C., Rudnick R. L. and McDonough W. F. (2015) Processes controlling delta Li-7 in rivers illuminated by study of streams and groundwaters draining basalts. Earth Planet. Sci. Lett. 409, 212-224.

Lynch J. A. and Corbett E. S. (1985) Source-area variability during peak flow. In Drain. Div. Am. Soc. Civ. Eng. (eds. E. B. Jones, T. J. Ward and J. Irrig) ASCE, Reston, VA, pp. 300-307.

Ma L., Chabaux F., Pelt E., Blaes E., Jin L. and Brantley S. L. (2010) Regolith Production Rates Calculated with Uranium-series Isotopes at the Susquehanna/Shale Hills Critical Zone Observatory. Earth Planet. Sci. Lett. 297, 211-225.

Ma L., Jin L. and Brantley S. L. (2011a) Geochemical behaviors of different element groups during shale weathering at the Susquehanna/Shale Hills Critical Zone Observatory. Appl. Geochemistry 26, S89-S93.

Ma L., Jin L. and Brantley, S. L. (2011b) How mineralogy and slope aspect affect REE release and fractionation during shale weathering in the Susquehanna/Shale Hills Critical Zone Observatory. Chem. Geol. 290, 31-49.

Ma L., Chabaux F., West N., Kirby E., Jin L. and Brantley S.L. (2013) Regolith production and transport in the Susquehanna Shale Hills Critical Zone Observatory, Part 1: Insights from U-series isotopes. J. Geophys. Res. Earth Surf. 118, 722-740.

Ma L., Konter J., Herndon E., Jin L., Steinhoefel G., Sanchez D. and Brantley S. L. (2014) Quantifying an early signature of the industrial revolution from lead concentrations and isotopes in soils of Pennsylvania, USA. Anthropocene 7, 16-29.

Ma L., Teng F.-Z., Jin L., Ke S., Yang, W., Gu H.-O. and Brantley S. L. (2015) Magnesium isotope fractionation during shale weathering in the Shale Hills Critical Zone Observatory :

Accumulation of light $\mathrm{Mg}$ isotopes in soils by clay mineral transformation. Chem. Geol. 397, 37-50.

Mansor M. and Fantle M. S. (2019) A novel framework for interpreting pyrite-based Fe isotope records of the past. Geochim. Cosmochim. Acta 253, 39-62.

Marriott C. S., Henderson G. M., Crompton R., Staubwasser M. and Shaw, S. (2004) Effect of mineralogy, salinity, and temperature on $\mathrm{Li} / \mathrm{Ca}$ and $\mathrm{Li}$ isotope composition of calcium carbonate. Chem. Geol. 212, 5-15.

Meek K., Derry L., Spark, J. and Cathles L. (2016) Sr-87/Sr-86, Ca/Sr, and Ge/Si ratios as tracers of solute sources and biogeochemical cycling at a temperate forested shale catchment, central Pennsylvania, USA. Chem. Geol. 445, 84-102.

Millot R., Petelet-Giraud E., Guerrot C. and Negrel P. (2010a) Multi-isotopic composition (delta Li-7delta B-11-delta D-delta O-18) of rainwaters in France: Origin and spatio-temporal characterization. Appl. Geochemistry 25, 1510-1524.

Millot R., Vigier N. and Gaillardet, J. (2010b) Behaviour of lithium and its isotopes during weathering in the Mackenzie Basin, Canada. Geochim. Cosmochim. Acta 74, 3897-3912.

Misra S. and Froelich P. N. (2012) Lithium Isotope History of Cenozoic Seawater: Changes in Silicate Weathering and Reverse Weathering. Science 335, 818-823.

Negrel P., Millot R., Guerrot C., Petelet-Giraud E., Brenot A. and Malcuit E. (2012) Heterogeneities and interconnections in groundwaters: Coupled B, Li and stable-isotope variations in a large aquifer system (Eocene Sand aquifer, Southwestern France). Chem. Geol. 296, 83-95.

Noireaux J., Gaillardet, J., Sullivan P. L. and Brantley, S. L. (2014) Boron Isotope Fractionation in Soils at Shale Hills CZO. Procedia Earth Planet. Sci. 10, 218-222. 
Noireaux J., Sullivan P., Gaillardet J., Louvat P., Steinhoefel G. and Brantley S. L (in press) Developing boron isotopes to elucidate shale weathering in the critical zone. Chem. Geol. (2020) doi: https://doi.org/10.1016/j.chemgeo.2020.119900.

Peucker-Ehrenbrink B. and Fiske G. J. (2019) A continental perspective of the seawater Sr-87/Sr-86 record: A review. Chem. Geol. 510, 140-165.

Peucker-Ehrenbrink B. and Ravizza G. (2000) The marine osmium isotope record. Terra Nova 12, 205219.

Phan T. T., Capo R. C., Stewart B. W., Macpherson G. L., Rowan E. L. and Hammack R. W. (2016) Factors controlling Li concentration and isotopic composition in formation waters and host rocks of Marcellus Shale, Appalachian Basin. Chem. Geol. 420, 162-179.

Pistiner J. S. and Henderson G. M. (2003) Lithium-isotope fractionation during continental weathering processes. Earth Planet. Sci. Lett. 214, 327-339.

Pogge von Strandmann, P. A. E., Burton K. W., James R. H., van Calsteren P., Gislason S. R. and Mokadem F. (2006) Riverine behaviour of uranium and lithium isotopes in an actively glaciated basaltic terrain. Earth Planet. Sci. Lett. 251, 134-147.

Pogge von Strandmann P. A. E., Burton K. W., James R. H., van Calsteren P. and Gislason, S. R. (2010) Assessing the role of climate on uranium and lithium isotope behaviour in rivers draining a basaltic terrain. Chem. Geol. 270, 227-239.

Pogge von Strandmann P. A. E., Opfergelt S., Lai Y.-J., Sigfusson B., Gislason S. R. and Burton K. W. (2012) Lithium, magnesium and silicon isotope behaviour accompanying weathering in a basaltic soil and pore water profile in Iceland. Earth Planet. Sci. Lett. 339, 11-23.

Pogge von Strandmann P. A. E., Porcelli D., James R. H., van Calsteren P., Schaefer B., Cartwright I., Reynolds B. C. and Burton K. W. (2014) Chemical weathering processes in the Great Artesian Basin: Evidence from lithium and silicon isotopes. Earth Planet. Sci. Lett. 406, 24-36.

Pogge von Strandmann P. A. E., Jenkyns H. C. and Woodfine R. G. (2013) Lithium isotope evidence for enhanced weathering during Oceanic Anoxic Event 2. Nat. Geosci. 6, 668-672.

Pogge von Strandmann P. A. E., Vaks A., Bar-Matthews M., Ayalon A., Jacob E. and Henderson G. M. (2017a) Lithium isotopes in speleothems: Temperature-controlled variation in silicate weathering during glacial cycles. Earth Planet. Sci. Lett. 469, 64-74.

Pogge von Strandmann P. A. E, Frings P. J. and Murphy M. J. (2017b) Lithium isotope behaviour during weathering in the Ganges Alluvial Plain. Geochim. Cosmochim. Acta 198, 17-31.

Qu Y. and Duffy C. J. (2007) A semi-discrete finite volume formulation for multiprocess watershed simulation. Water Resour. Res. 43, 1-18.

Riebe C. S., Hahme W. J. and Brantley S. L. (2017) Controls on deep critical zone architecture: a historical review and four testable hypotheses. Earth Surf. Process. Landf. 42, 128-156.

Roberts J., Kaczmarek K., LangernG., Skinner L. C., Bijma J., Bradbury H., Turchyn A. V., Lamy F. and Misra S. (2018) Lithium isotopic composition of benthic foraminifera: A new proxy for paleo$\mathrm{pH}$ reconstruction. Geochim. Cosmochim. Acta 236, 336-350.

Romer R.L. and Meixner A. (2014) Lithium and boron isotopic fractionation in sedimentary rocks during metamorphism - The role of rock composition and protolith mineralogy. Geochim. Cosmochim. Acta 128, 158-177.

Romer R. L., Meixner A. and Hahne K. (2014) Lithium and boron isotopic composition of sedimentary rocks - The role of source history and depositional environment: A 250 Ma record from the Cadomian orogeny to the Variscan orogeny. Gondwana Res. 26, 1093-1110.

Rosner M., Ball L., Peucker-Ehrenbrink B., Blusztajn J., Bach W. and Erzinger J. (2007) A simplified, accurate and fast method for lithium isotope analysis of rocks and fluids, and delta Li-7 values of seawater and rock reference materials. Geostand. Geoanal. Res. 31, 77-88.

Rudnick R.L., Tomascak P. B., Njo H. B. and Gardner L. R. (2004) Extreme lithium isotopic fractionation during continental weathering revealed in saprolites from South Carolina. Chem. Geol. 212, 45-57.

Rugenstein J. K. C., Ibarra D. E. and von Blanckenburg F. (2019) Neogene cooling driven by land surface reactivity rather than increased weathering fluxes. Nature 571, 99-102. 
Ryu J. S., Vigier N., Lee S. W., Lee K. S. and Chadwick O. A. (2014) Variation of lithium isotope geochemistry during basalt weathering and secondary mineral transformations in Hawaii. Geochim. Cosmochim. Acta 145, 103-115.

Sauzeat L., Rudnick R. L., Chauvel C., Garcon M. and Tang M. (2015) New perspectives on the Li isotopic composition of the upper continental crust and its weathering signature. Earth Planet. Sci. Lett. 428, 181-192.

Shi Y., Davis K. J., Zhang F. and Duffy C. J. (2014) Evaluation of the parameter sensitivity of a coupled land surface hydrologic model. J. Hydrometeorol. 15, 279-299.

Smith L. A., Eissenstat D. M. and Kaye M. W. (2017) Variability in aboveground carbon driven by slope aspect and curvature in an eastern deciduous forest, USA. Can. J. For. Res. 47, 149-158.

Sullivan P. L., Hynek S. A., Gu X., Singha K., White T., West N., Kim H., Clarke B., Kirby E., Duffy C. and Brantley S. L. (2016a) Oxidative dissolution under the channel leads geomorphogogical evolution at the Shale Hills catchment. Am. J. Sci. 316, 981-1026.

Sullivan P. L., Ma L., West N., Jin L., Karwan D. L., Noireaux J., Steinhoefel G., Gaines K. P., Eissenstat D. M., Gaillardet J., Derry L. A., Meek K., Hynek S. and Brantley S. L. (2016b) CZ-tope at Susquehanna Shale Hills CZO: Synthesizing multiple isotope proxies to elucidate Critical Zone processes across timescales in a temperate forested landscape. Chem. Geol. 445, 103-119.

Sullivan P. L., Godderis Y., Shi Y., Gu X., Schott J., Hasenmueller E. A., Kaye J., Duffy C., Jin L. and Brantley S. L. (2019) Exploring the Effect of Aspect to Inform Future Earthcasts of ClimateDriven Changes in Weathering of Shale. J. Geophys. Res. Earth Surf. 124, 974-993.

Teng F.-Z., McDonough W. F., Rudnick R. L., Dalpe C., Tomascak P. B., Chappell B. W. and Gao S. (2004) Lithium isotopic composition and concentration of the upper continental crust. Geochim. Cosmochim. Acta 68, 4167-4178.

Teng F.-Z., Li W.-Y., Rudnick R. L. and Gardner L. R. (2010) Contrasting lithium and magnesium isotope fractionation during continental weathering. Earth Planet. Sci. Lett. 300, 63-71.

Thomas E., Lin H., Duffy C., Sullivan P. L., Holmes G.H., Brantley S. L. and Jin L. (2013) Spatiotemporal patterns of water stable isotope compositions at the Shale Hills Critical Zone: Linkages to subsurface hydrologic processes. Vadose Zone J. 12, vzj2013.01.0029.

Valletta R. D., Willenbring J. K., Passchier S. and Elmi C. (2018) Be-10/Be-9 Ratios Reflect Antarctic Ice Sheet Freshwater Discharge During Pliocene Warming. Paleoceanogr. Paleocl. 33, 934-944.

Verney-Carron A., Vigier N. and Millot R. (2011) Experimental determination of the role of diffusion on Li isotope fractionation during basaltic glass weathering. Geochim. Cosmochim. Acta 75, 3452-3468.

Vigier N. and Godderis Y. (2015) A new approach for modeling Cenozoic oceanic lithium isotope paleo-variations: the key role of climate. Clim. Past. 11, 635-645.

Vigier N., Decarrea, A., Millot R., Carignan J., Peti, S. and France-Lanord C. (2008) Quantifying Li isotope fractionation during smectite formation and implications for the Li cycle. Geochim. Cosmochim. Acta 72, 780-792.

Vigier N., Gislason S. R., Burton K. W., Millot R. and Mokadem F. (2009) The relationship between riverine lithium isotope composition and silicate weathering rates in Iceland. Earth Planet. Sci. Lett. 287, 434-441.

Walker J. C. G., Hays P. B.,Kasting J. F. (1981) A negative feedback mechanism for the long-term stabilization of Earth's surface temperature. J. Geophys. Res. Earth Surf. 86, 9776-9782.

Wanner C., Sonnenthal E. L. and Liu X.-M. (2014) Seawater delta Li-7: A direct proxy for global $\mathrm{CO}_{2}$ consumption by continental silicate weathering? Chem. Geol. 381, 154-167.

Wanner C., Bucher K., Pogge von Strandmann, P. A. E., Waber H. N. and Pettke T. (2017) On the use of $L i$ isotopes as a proxy for water-rock interaction in fractured crystalline rocks: A case study from the Gotthard rail base tunnel. Geochim. Cosmochim. Acta 198, 396-418.

West N., Kirby E., Bierman P. R. and Rood D. (2011) Preliminary estimates of regolith generation and mobility in the Susquehanna Shale Hills Critical Zone Observatory, Pennsylvania, using meteoric ${ }^{10} \mathrm{Be}$. Appl. Geochemistry 26, S146-S148. 
West N., Kirby E., Bierman P. R., Slingerland R., Ma L., Rood D. and Brantley S.L. (2013) Regolith production and transport at the Susquehanna Shale Hills Critical Zone Observatory: Part 2 Insights from meteoric ${ }^{10} \mathrm{Be}$. J. Geophys. Res. Earth Surf. 118, 1877-1896.

West N., Kirby E., Bierman P. R. and Clarke B. A. (2014) Aspect-dependent variations in regolith creep revealed by meteoric ${ }^{10} \mathrm{Be}$. Geology 42, 507-510.

West N., Kirby E., Nyblade A. A. and Brantley S. L. (2019) Climate preconditions the Critical Zone: Elucidating the role of subsurface fractures in the evolution of asymmetric topography. Earth Planet. Sci. Lett. 513, 197-205.

Weynell M., Wiechert U. and Schuessler J. A. (2017) Lithium isotopes and implications on chemical weathering in the catchment of Lake Donggi Cona, northeastern Tibetan Plateau. Geochim. Cosmochim. Acta 213, 155-177.

Willenbring J. K. and von Blanckenburg F. (2010) Long-term stability of global erosion rates and weathering during late-Cenozoic cooling. Nature 465, 211-214.

Williams L. B. and Hervig R. L. (2005) Lithium and boron isotopes in illite-smectite: The importance of crystal size. Geochim. Cosmochim. Acta 69, 5705-5716.

Williams L. B., Elliott W. C. and Hervig R. L. (2015) Tracing hydrocarbons in gas shale using lithium and boron isotopes: Denver Basin USA, Wattenberg Gas Field. Chem. Geol. 417, 404-413.

Wilson M. J. (2004) Weathering of the primary rock-forming minerals: processes, products and rates. Clay Miner. 39, 233-266.

Wimpenny J., James R. H., Burton K. W., Gannoun A., Mokadem F. and Gislason S. R. (2010) Glacial effects on weathering processes: New insights from the elemental and lithium isotopic composition of West Greenland rivers. Earth Planet. Sci. Lett. 290, 427-437.

Wimpenny J., Colla C. A., Yu P., Yin Q. Z., Rustad J. R. and Casey W. H. (2015) Lithium isotope fractionation during uptake by gibbsite. Geochim. Cosmochim. Acta 168, 133-150.

Wittmann H., von Blanckenburg F., Mohtadi M., Christl M. and Bernhardt A. (2017) The competition between coastal trace metal fluxes and oceanic mixing from the Be-10/Be-9 ratio: Implications for sedimentary records. Geophys. Res. Lett. 44, 8443-8452.

Xiao D., Shi Y., Brantley S. L., Forsythe B., DiBase R., Davis K. and Li L. (2019) Streamfow generation from catchments of contrasting lithologies: The Role of soil Properties, topography, and catchment size.Water Resour. Res. 55, 9234-9257.

Yesavage T., Fantle M., Vervoort J., Mathur R., Jin L., Liermann L. J. and Brantley S. L. (2012) Fe cycling in the Shale Hills Critical Zone Observatory, Pennsylvania: An analysis of biogeochemical weathering and $\mathrm{Fe}$ isotope fractionation. Geochim. Cosmochim. Acta 99, 18-38.

Zhang L. B., Chan L. H. and Gieskes J. M. (1998) Lithium isotope geochemistry of pore waters from Ocean Drilling Program Sites 918 and 919, Irminger Basin. Geochim. Cosmochim. Acta 62, 2437-2450. 